\title{
Les poteries néolithiques à décor peint " noir sur rouge " en Grèce du Nord : matières premières et production
}

\author{
Dimitra Malamidou, Zoï TsiRTsoni, Paraskévi Yiouni, \\ Laurent LESPEZ, Vassilis KILIKOGLOU, Alexandra TSOLAKIDOU*
}

Des poteries décorées avec une peinture noire sur fond rouge se trouvent fréquemment dans les niveaux de la fin du Néolithique Récent (4800/4700-3900/3800 av. J.-C.) en Grèce du Nord. Particulièrement abondantes en Macédoine orientale, elles sont présentes en quantités plus ou moins importantes dans les autres parties de la Macédoine (y compris la haute vallée de la Struma, en Bulgarie du Sud-Ouest), ainsi qu'en Thrace et en Thessalie (fig. 1). Ces poteries sont utilisées depuis longtemps par les chercheurs comme critère pour la datation relative et pour l'attribution « culturelle» des assemblages archéologiques mis au jour dans ces régions. Cependant, elles n'avaient jamais fait l'objet d'une étude approfondie, susceptible de mettre en avant leur caractère d'artefacts issus d'un ou de plusieurs centres de production, que l'on devrait tâcher de localiser.

Tel était, précisément, le but du programme de recherches pluridisciplinaires élaboré en 1999 par les archéologues D. Malamidou, P. Yiouni et Z. Tsirtsoni. Le programme, qui a été réalisé entre 2000 et 2004 grâce à un financement commun de l'École française d'Athènes ${ }^{1}$ et du CNRS, a bénéficié de la participation active de L. Lespez, géomorphologue, et de V. Kilikoglou et A. Tsolakidou, chimistes².

* D. Malamidou et P. Yiouni, ministère grec de la Culture ; Z. Tsirtsoni, UMR 5138 archéométrie et archéologie, CNRS/université Lyon II et Lyon I ; L. Lespez, GEOPHEN-UMR 6554, CNRS/université de Caen ; V. Kilikoglou et A. Tsolakidou, Laboratoire d'archéométrie du Centre national de recherches scientifiques Démokritos.

1. Nous tenons à remercier les directeurs successifs de l'ÉFA, Roland Étienne et Dominique Mulliez, pour leur soutien constant et substantiel à ce projet.

2. Sur le déroulement des travaux, voir les rapports préliminaires parus dans $B C H 125$ (2001), p. 630-632, et 126 (2002), p. 547-549. 

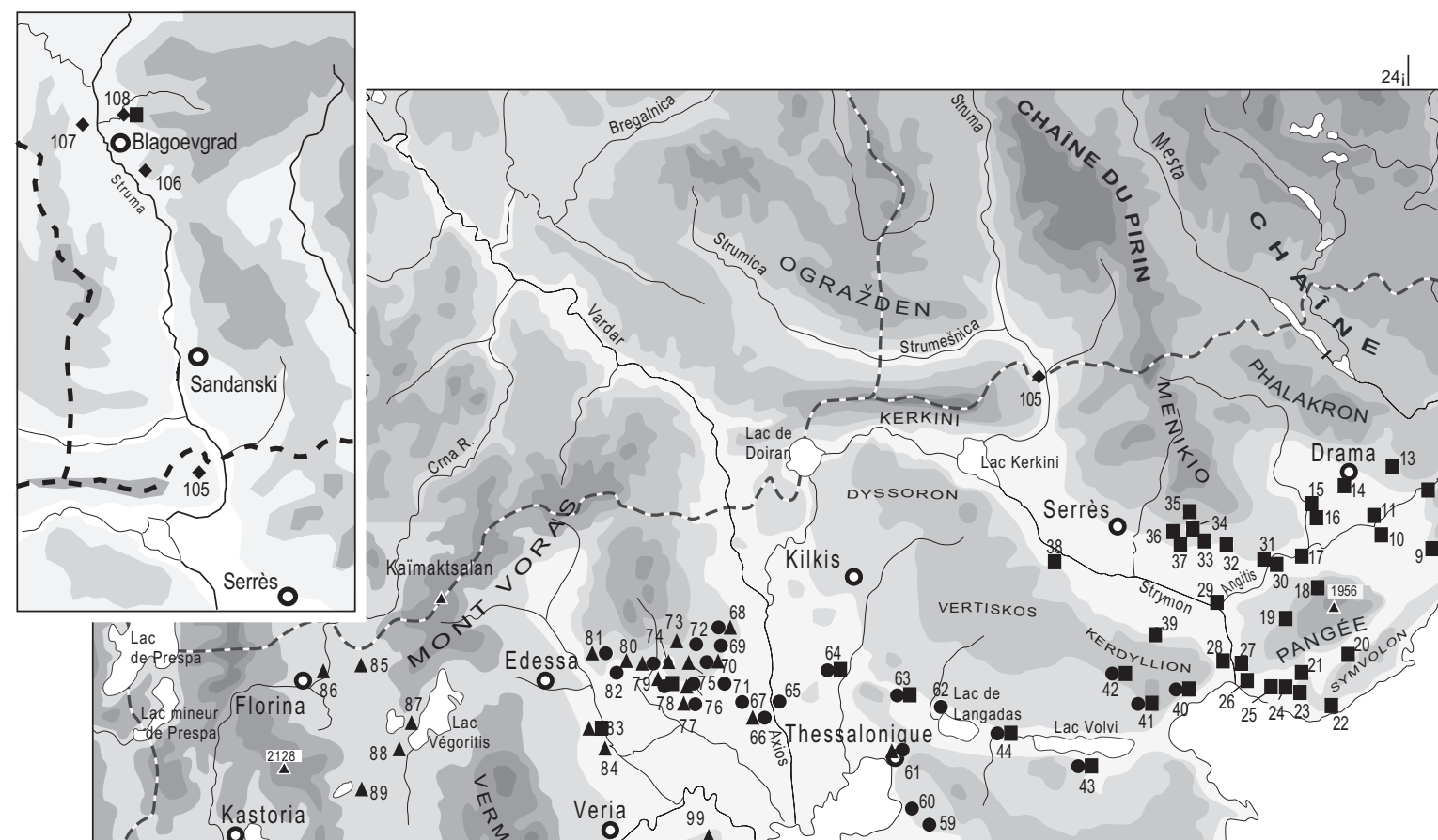

24il
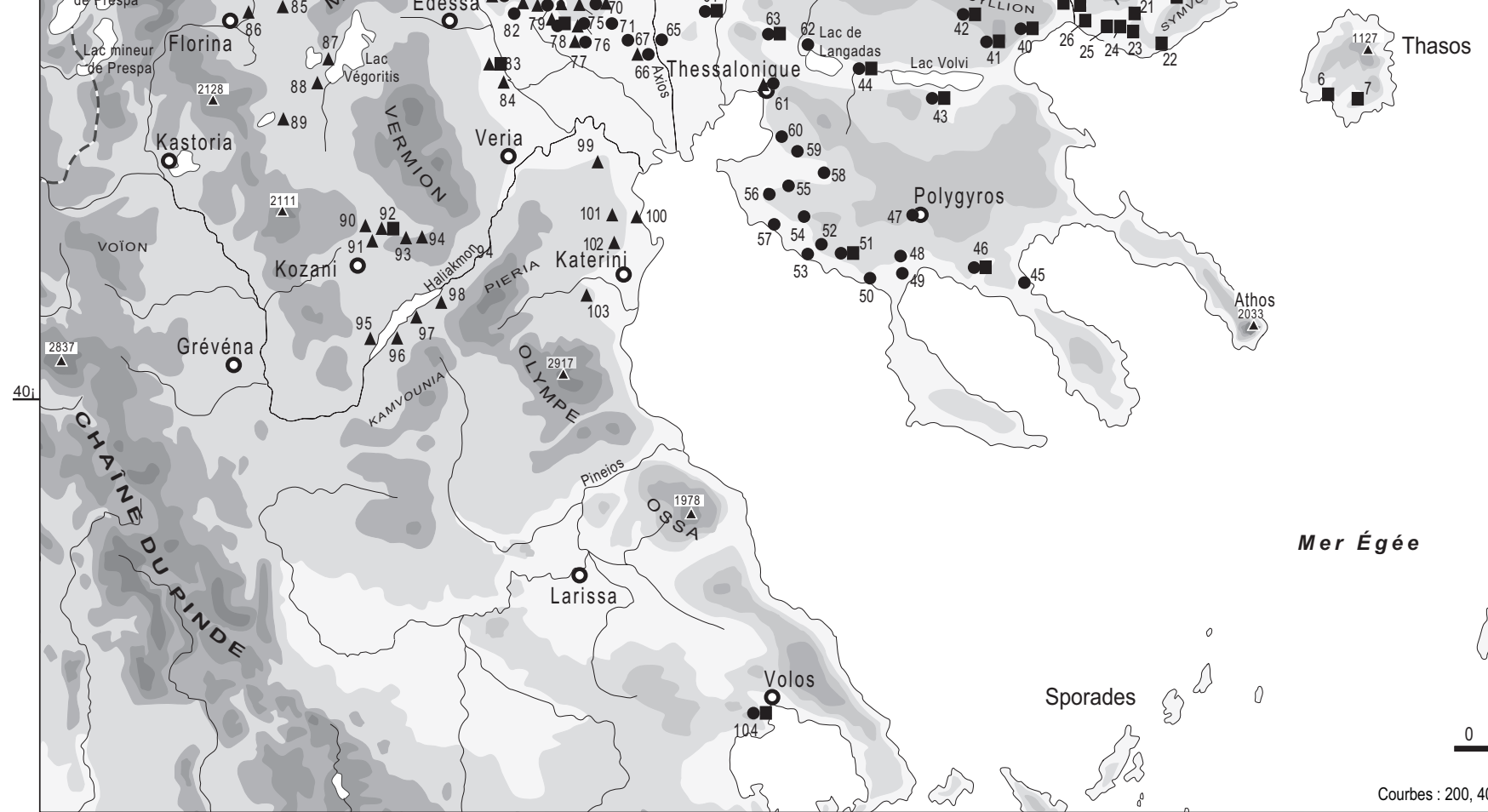

2002-93 @ Fond de carte Catherine FINETIN

Traitement Dimitra MALAMIDOU

Faciès 1

• Faciès 2

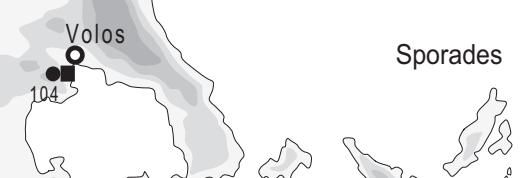

- Faciès 3

Faciès 4
Mer Égée

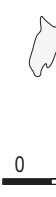

Courbes : 200,400 

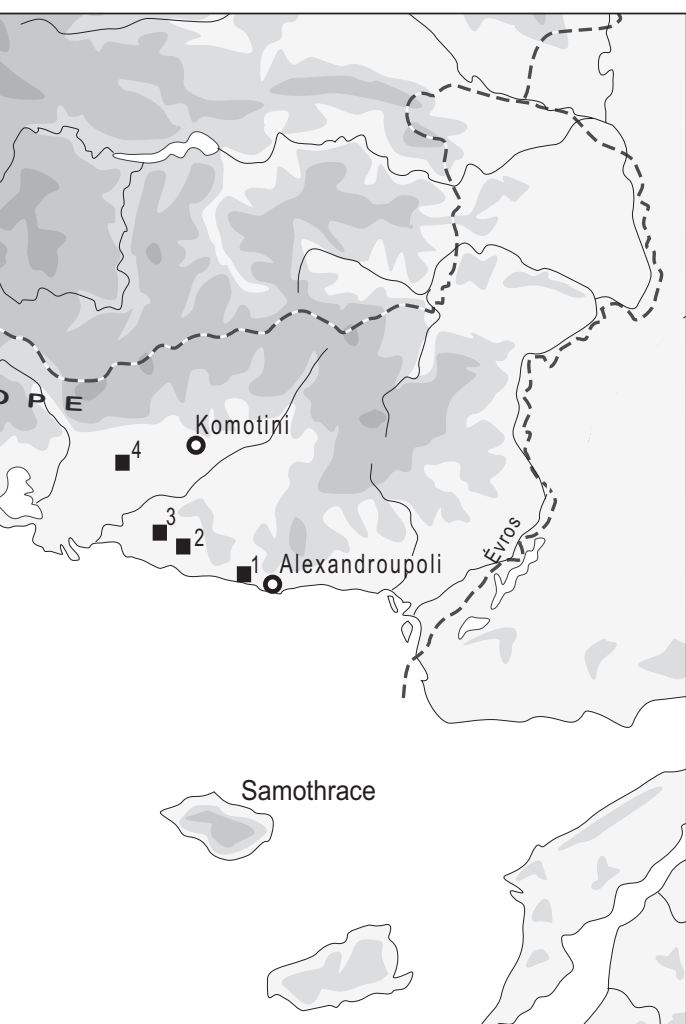

Lemnos
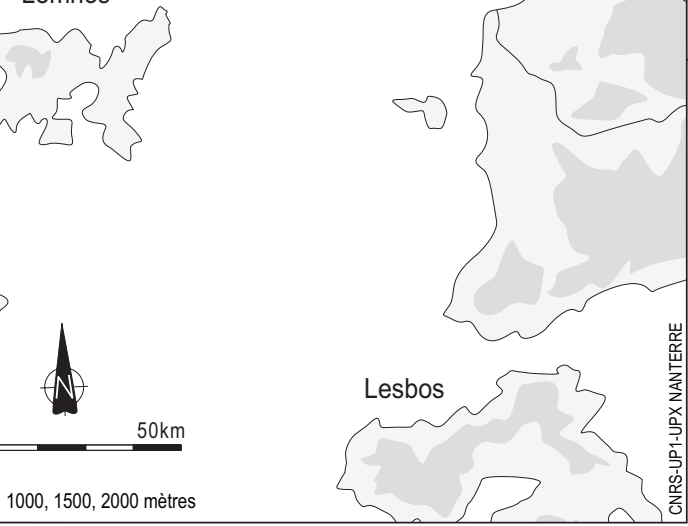

Maison René Ginouvès - Archéologie \& Ethnologie
1. Makri

2. Grotte de Maronée

3. Proskynitès

4. Paradimi

5. Paradisos

6. Liménaria

7. Kastri

8. Polystylo

9. Dikili Tash

10. Kalambaki

11. Doxato

12. Adriani-Agora

13. Kalliphytos

14. Arkadikos, Drama

15. Mégalokambos

16. Sitagri

17. Paliokostra, gare d'Angista

18. Néa Baphra

19. Marina, Mikro Souli

20. Mousthéni

21. Gialimia, Podochori

22. Loutra Élefthéron

23. Akropotamos

24. Kokkinochori

25. Galepsos

26. Ofrynio

27. Colline 133-

Amphipolis

28. Kryonéri

29. Fidokoryfi

30. Dimitra

31. Aïri Baïri, Dimitra

32. Tholos

33. Toumba

34. Profitis Ilias,

Pentapoli

35. Aghio Pnevma

36. Fakistra, Chrysso

37. Gare de Chrysso

38. Kastri, Strymoniko

39. Zervochori

40a. Asprovalta,

Aghia Lydia

40b. Asprovalta,

Platôma

41. Aréthoussa
42. Sképasto (Melisia)

43. Néa Apollonia C

(Mésè Alani

Mésopotamou)

44. Stivos A et B

45. Vetrino, Aghios

Nikolaos

46. Ormylia A

47. Aghios Nikolaos,

Polygyros

48. Olynthe

49. Haghios Mamas

50. Flogita

51. Gili, Néa Triglia

52. Néa Syllata B

53. Néa Kallikratia

54. Kastraki, Néa Gonia

55. Messimériani

Toumba,

Trilofos B

56. Épanomi D

57. Kritsana

58. Vassilika C

59. Néa Rédestos

60. Thermi B

61. Stavroupoli

62. Périvolaki

63. Drymos

64. Xylokératia

65. Géfyra

66. Valtochori

67. Chalkidona

68. Evropos

69. Dytiko

70. Agrosykia

71. Koufalia

72. Leptokarya A

73. Asvestario A

74. Ambéliès

75. Damiano

76. Archontiko

77. Paralimni

78. Giannitsa A et B

79. Aravissos

80. Plagiari A

81. Mandalo A

82. Drosséro
83. Polyplatanos

84. Toumba Giannissas

85. Méliti (Staro Sélo)

86. Arménochori

87. Métamorphosi

Sôtiros, Aghios

Pandéléimon

88. Nissi, Végora

89. Monastiraki,

Anargyri

90. Pontokomi

91. Drépano

92. Mégalo Nissi Galanis

93. Aghios Dimitrios, Koilada

94. Xéropigado

95. Aiani, Palla Rachi

96. Goules, Varéméni

97a. Servia, Kolitsaki

97b. Servia, Zigra

97c. Servia, Géfyra

98. Velvendos, Vassilara Rachi

99. Paliambéla

100. Makriyalos

101. Sfendami

102. Sévasti

103. Kondariotissa

104. Pefkakia

105. Promachon-

Topolnitsa

106. Strumsko

107. Bălgarčevo

108. Slatino

Fig. 1. - Carte de la Grèce du Nord avec les sites du Néolithique Récent qui ont livré des céramiques " noir sur rouge ", indiquant la répartition des quatre faciès régionaux. 


\section{LES RECHERCHES ANTÉRIEURES ET LA PROBLÉMATIQUE DE L'ENQUÊTE}

Des fragments d'une céramique à décor peint noir sur rouge ont été recueillis pour la première fois en Macédoine lors de prospections effectuées à la fin des années 1910. Leurs descriptions contiennent, dès le début, les mots qui vont constituer la «marque » de cette catégorie : «noir ou brun foncé sur fond rouge ${ }^{3}$ ".

Avec les premières fouilles sur les sites d'Olynthe ${ }^{4}\left(\right.$ fig. $\left.1, n^{\circ} 48\right)$ et de Kritsana ${ }^{5}\left(n^{\circ} 57\right)$ dans les années 1930, on établit ses caractéristiques en tant que catégorie céramique spécifique ; il s'agit d'une poterie " painted in brownish-black or dark brown-black colors on a red surface ${ }^{\star}$ ", caractérisée par " a well-purified clay, fired light red throughout, with a smooth but not highly polished surface 7 . Des fragments similaires ont été recueillis à peu près aux mêmes dates en Macédoine orientale, dans les fouilles d'Akropotamos $\left(n^{\circ} 23\right)$ et de Polystylo $\left(n^{\circ} 8\right)$, tandis qu'en 1955 on introduit le terme de "GalepsosWare9 " (= céramique de Galepsos) pour décrire la céramique "noir sur rouge » collectée sur le site du même nom (no 25 ). Les premiers aperçus synthétiques apparaissent dans les années $1960^{10}$. On y fixe des critères d'identification macroscopique précis, relevant de l'aspect et de la qualité de la pâte et de la peinture, de la forme et de l'épaisseur des fragments, du répertoire des motifs décoratifs.

3. F. B. Welch, «Macedonia : Prehistoric Pottery», ABSA 23 (1918-1919), p. 44-50, sp. p. 44-46 et fig. 1 ; L. REY, "Observations sur les premiers habitats de la Macédoine recueillies par le Service archéologique de l'Armée d'Orient, 1916-1919 (région de Salonique) ", BCH 41-43 (1917-1919), p. 202.

4. G. E. MylonAs, Excavations at Olynthus, I. The Neolithic Settlement (1929), p. 46-49, pl. I, fig. 66-69. Voir aussi W. A. Heurtley, Prehistoric Macedonia (1939), p. 75, 161 et fig. 32.

5. Ibid., p. 75, 159-160 et fig. 28, 29, 31.

6. G. E. MylOnAS, op. cit. (supra, n. 4), p. 50.

7. W. A. HEURTLEY op. cit. (supra, n. 4), p. 74-75.

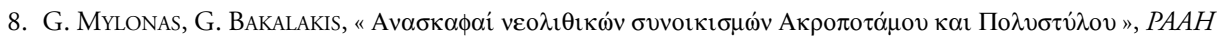
1938, p. 103-111, fig. 2 ; G. MYLONAS, "The Site of Akropotamos and the Neolithic Period of Macedonia ", AJA 45 (1941), p. 557-576, fig. 2.

9. F. SCHACHERMEYR, Die ältesten Kulturen Griechenlands (1955), p. 108-109.

10. D. H. FrenCH, «Late Chalcolithic Pottery in Northwest Turkey and the Aegean ", AS 11 (1961) p. 99-142, sp. p. $114-116$; id., « Prehistoric Pottery from Macedonia and Thrace ", PZ 42 (1964) p. 30-48, sp. p. 32-33 et fig. 3, 4 ; J. Deshayes, M. Garašanin, « Note sur la céramique de Galepsos », BCH 88 (1964), p. 51-66. 
La multiplication des prospections et l'ouverture de nouvelles fouilles en Macédoine orientale $^{11}$, centrale ${ }^{12}$, occidentale ${ }^{13}$ et en Thrace méridionale ${ }^{14}$ ont permis de mettre au jour un abondant matériel et de considérer l'ampleur de la répartition de ces céramiques. Ces dernières caractérisent un horizon stratigraphique que l'on date de la fin du Néolithique Récent local, entre le deuxième quart du $\mathrm{V}^{\mathrm{e}}$ et le début du $\mathrm{IV}^{\mathrm{e}}$ millénaire av. J.-C. (4800/4700-3900/3800 av. J.-C.). Leur caractère facilement reconnaissable même sur de petits fragments et leur position stratigraphique assurée font des céramiques « noir sur rouge » un excellent instrument pour la datation relative. C'est à ce titre de " céramiques diagnostiques » qu'elles sont le plus souvent évoquées dans la littérature des années 19702000.

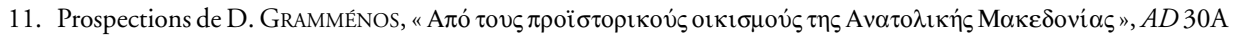

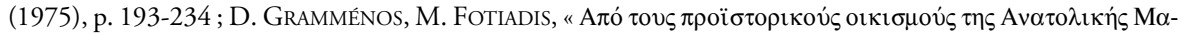

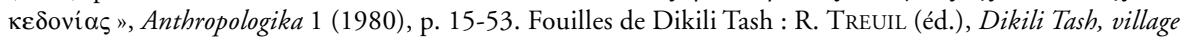
préhistorique de Macédoine orientale, I. Fouilles de Jean Deshayes (1961-1975), vol. 1, BCH Suppl. XXIV (1992), p. 11-17, 19-37 ; J.-P. Demoule, "Les formes et les décors des récipients du Néolithique Récent (Chalcolithique) : description, évolution et contexte régional ", in R. TREuIL (éd.), Dikili Tash, village préhistorique de Macédoine orientale, I. Fouilles de Jean Deshayes (1961-1975), vol. 2, BCH Suppl. 37 (2004), p. 163-270. Fouilles de Sitagri : J. Evans, "The Pottery of Phase III ", in C. RENFreW, M. GimbUTAS, E. ElsTer (éds), Excavations at Sitagroi : a Prehistoric Village in Northeastern Greece, vol. I (1986), p. 393-428. Fouille de Paradisos : P. HeLLSTRÖm (éd.), Paradeisos. A Late Neolithic Settlement in Aegean Thrace (1987). Fouille de Dimitra :

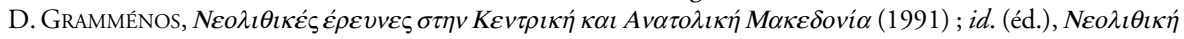

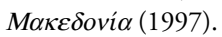

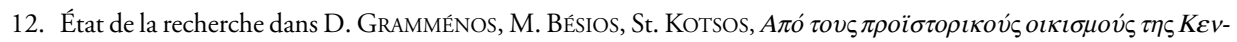

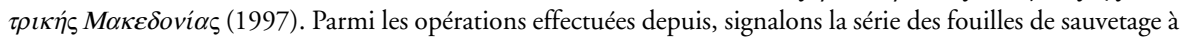
Stavroupoli (banlieue Nord de Thessalonique) : D. GrammÉnOS, St. KoTsos (éds), $\Sigma \omega \sigma \tau \imath \kappa \varepsilon ́ \varsigma \alpha v \alpha \sigma \kappa \alpha \phi \varepsilon ́ \varsigma \sigma \tau o$

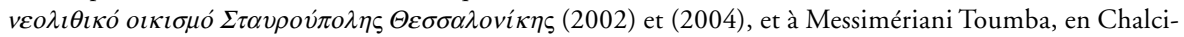

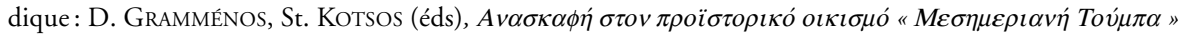

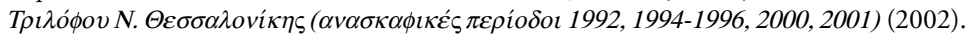

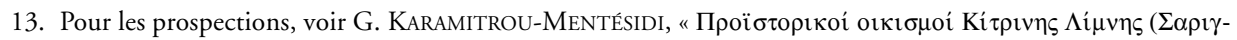

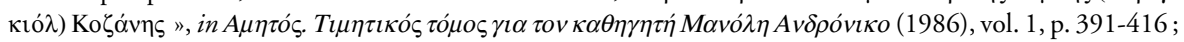

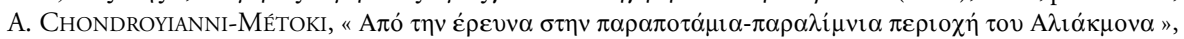

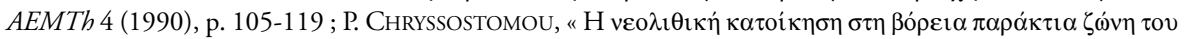

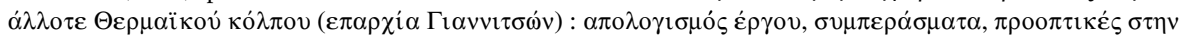

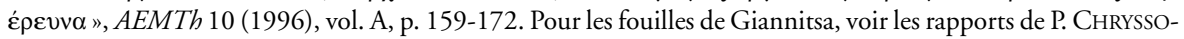
STOMOU dans AEMTh 3 (1989), p. 119-134, 5 (1991), p. 111-125, et 7 (1993), p. 135-136. Pour les fouilles de Polyplatano, voir les rapports de L. STÉPHANI et N. MÉROUSSIS dans AEMTh 11 (1997), p. 93-99, 12 (1998), p. 383-393, et 14 (2000), p. 555-562. Pour les fouilles de Makrygialos, synthèse dans M. PAPPA, M. BÉSIOS, "The Makriyalos Project : Rescue Excavations at the Neolithic Site of Makriyalos, Pieria, Northern Greece ", in P. Halstead (éd.), Neolithic Society in Greece (1999), p. 108-120.

14. Les principaux sites fouillés sont Paradimi (G. BaKalakis, A. Sakellariou, Paradimi [1981]) et Makri (N. Efstratiou et al., "Excavations at the Neolithic Settlement of Makri, Thrace, Greece (1988-1996) : A Preliminary Report ", Saguntum 31 [1998], p. 11-62). 
La répartition spatiale de ces céramiques n'est évoquée d'habitude que pour souligner les rapports culturels ou " commerciaux » entre des habitats plus ou moins distants. Ainsi la découverte, sur le site de Pefkakia en Thessalie (fig. 1, no 104), de quelques fragments "noir sur rouge » rappelant fort ceux trouvés en Macédoine orientale suscite des discussions sur les réseaux d'échanges en Grèce néolithique ${ }^{15}$. De même, la découverte de tessons « noir sur rouge » à Slatino, dans la haute vallée de la Struma en Bulgarie ( $\left.n^{\circ} 108\right)$, confirmerait l'appartenance de ce site à une aire culturelle commune avec les sites de la Macédoine orientale grecque, dite de Slatino-Dikili Tash ${ }^{16}$. Mais les modalités de production dans les zones présumées « centrales " ne font l'objet d'aucune discussion, ou presque. Sur ce point, on en est resté à l'hypothèse émise par D. Théocharis au début des années 1970, qui, s'appuyant sur le taux de répartition des céramiques " noir sur rouge», plaçait le centre (ou les centres) de production parmi les sites de la basse vallée du Strymon, peut-être à Dimitra ${ }^{17}$ (no 30$)$.

La fouille de Kryonéri ${ }^{18}$, dans la basse vallée du Strymon justement (fig. 1, no 28), en 1996-1997, a apporté d'importants éléments nouveaux au dossier. Avec des céramiques «noir sur rouge » représentant $70 \%$ des céramiques décorées, cette découverte fut un bon motif pour ranimer la discussion sur cette production céramique spécifique. La question était de savoir : a) si l'ensemble des céramiques «noir sur rouge » de la Grèce du Nord était effectivement issu d'un seul centre de production ou de plusieurs, et b) si l'on pouvait identifier le (ou les) centre(s) en question avec un ou plusieurs sites du Néolithique Récent connus dans la région, dont Kryonéri.

Nos connaissances sur la technologie de ces céramiques en général, et sur les matières premières utilisées pour leur fabrication en particulier, étaient jusqu'alors relativement maigres. On savait qu'il s'agissait, généralement, de poteries faites avec une pâte riche en oxydes de fer, décorées avec une peinture noire à base d'oxydes de manganèse et cuites à une température de $900-960^{\circ} \mathrm{C}$. Mais les quelques études pétrographiques effectuées insistaient sur la finesse exceptionnelle des pâtes, qui étaient pratiquement dépourvues d'inclusions pouvant nous renseigner sur l'origine géologique des matériaux, alors que les rares analyses physico-chimiques portaient surtout sur la décoration (engobes et peinture)

15. H. J. WeISSHAaR, « Nordgriechischer Import im Kupferzeitlichen Thessalien », JRGZM 26 (1979), p. 114-130.

16. St. ČOHADZIEV, Slatino-praistoričeski selista (1997), p. 24-47.

17. D. ThÉOCHARIS, Prehistory of Eastern Macedonia and Thrace (1971), p. 18.

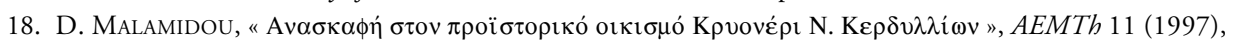
p. $509-522$. 
ou sur les températures de cuisson ${ }^{19}$. Par ailleurs, en l'absence d'études synthétiques récentes, on avait du mal à discerner, même à l'échelle d'une observation macroscopique/stylistique, d'éventuels groupes de céramiques " noir sur rouge ", susceptibles de représenter des productions de centres ou d' « ateliers » distincts.

La présente enquête s'est déployée autour de trois axes complémentaires, qui visaient à combler du mieux possible les lacunes de la recherche.

Le premier axe comporte une étude proprement archéologique, dont le but était de mettre en évidence, à travers une analyse macroscopique détaillée d'objets aussi nombreux et aussi bien préservés que possible, les éventuels groupements de matériel. Ces derniers pouvaient en effet suggérer des productions différentes, relevant de traditions potières distinctes.

Le deuxième axe comporte l'étude physico-chimique d'échantillons céramiques prélevés dans les différents groupes préalablement distingués d'après l'étude macroscopique. Le but était de voir si, pour chaque groupe macroscopique, les compositions chimiques des pâtes appartenaient à un seul ou à plusieurs groupes. L'existence de plusieurs groupes devait correspondre à des centres de production exploitant des sources de matières premières distinctes.

Enfin, le troisième axe comporte la localisation des sources de matières premières préhistoriques, à travers la comparaison de la composition chimique des céramiques avec celle de sédiments susceptibles d'avoir été utilisés par les potiers néolithiques. Une telle comparaison présupposait une enquête sur le terrain avec prélèvement d'échantillons de sédiments, puis analyse selon les mêmes méthodes que celles employées pour les échantillons céramiques.

19. E. Gardner, The Pottery Technology of the Neolithic Period in SE Europe, Ph. D., University of California (1978); ead., "Technical Analysis of the Ceramics", in E. Elster, C. RENFrEW (éds), Prehistoric Sitagroi : Excavations in Northeast Greece, 1968-1970, 2. The Final Report (2003), p. 283-295 ; L.-C. CourTOIS, "Les techniques de la céramique", in R. Treuil, op. cit. (supra, n. 11 [2004]), p. 1-25; T. C. DARVILL, "A Petrological Study of Pottery from Dimitra, East Macedonia ", in D. Gramménos, op. cit. (supra, n. 11 [1997]), p. 80-83 ; M. D. Kessisoglou, E. A. MirTsou, "Ceramic Technology in Dimitra during the Neolithic Period ", ibid., p. 84-90 ; P. YIOUNI, « Painted Pottery from East Macedonia, in North Greece : Technological Analysis of Decorative Techniques ", Documenta Praehistorica XXVII (2000), p. 199-214 ; ead., "Surface Treatment of Neolithic Vessels from Macedonia and Thrace ", ABSA 96 (2001), p. 1-25. 


\section{APPROCHE MACROSCOPIQUE ET GROUPES ARCHÉOLOGIQUES}

L'étude macroscopique a porté sur du matériel provenant de quelque 70 sites de Grèce du Nord connus par prospection, ainsi que de 36 sites ayant fait l'objet de fouilles ou de sondages $^{20}$. Les critères retenus étaient à la fois technologiques (aspect et texture de la pâte, aspect et coloration de la surface, aspect de la peinture) et morphologiques (éléments et organisation du décor, formes des vases).

\section{Différenciation de la production}

L'étude a permis de distinguer, au total, quatre faciès de poteries à décor peint " noir sur rouge ", chacun possédant ses propres traits techniques et morphologiques et présentant une répartition géographique différente (fig. 1).

\section{Faciès 1}

Le faciès 1 se caractérise par une pâte extrêmement fine, dense et légère. Les inclusions non plastiques visibles à l'œil nu sont très rares et de granulométrie fine : il s'agit le plus souvent de paillettes de mica, de grains de quartz, de grains calciques, ainsi que de petits grains d'hématite ou d'ocre. Des vacuoles de petite taille et de forme irrégulière, laissées par la combustion d'éléments végétaux fins, apparaissent rarement, en section ou en surface.

La couleur de la pâte est uniformément rouge ou rouge-orange, plus rarement brunrouge. En section, le cœur se présente le plus souvent oxydé, de la même couleur que les parois, plus rarement gris en raison d'une oxydation incomplète. Les surfaces, avec ou sans engobe, sont toujours soigneusement lissées et polies, et présentent un toucher lisse. Les engobes, quand ils existent, sont d'une couleur rouge ou rouge-orange, tandis que la peinture est noire ou brun-noir, mais aussi parfois grise ou même blanchâtre. Elle est généralement assez épaisse et couvrante, d'un aspect brillant. On constate parfois l'existence d'un deuxième engobe blanchâtre, peu épais et presque transparent, appliqué sur l'ensemble de la surface du vase, par dessus la peinture.

La gamme des formes de vases est large : écuelles, jattes, bols, pots, jarres, supports (fig. 2). L'épaisseur des parois varie selon les types et les dimensions des vases : elle peut

20. Étude réalisée dans le cadre d'une thèse : D. MALAmidOU, La céramique à décor peint "noir sur rouge " du Néolithique Récent II en Grèce du Nord : production, distribution et utilisation, thèse de doctorat, université de Paris IPanthéon-Sorbonne (2005). 

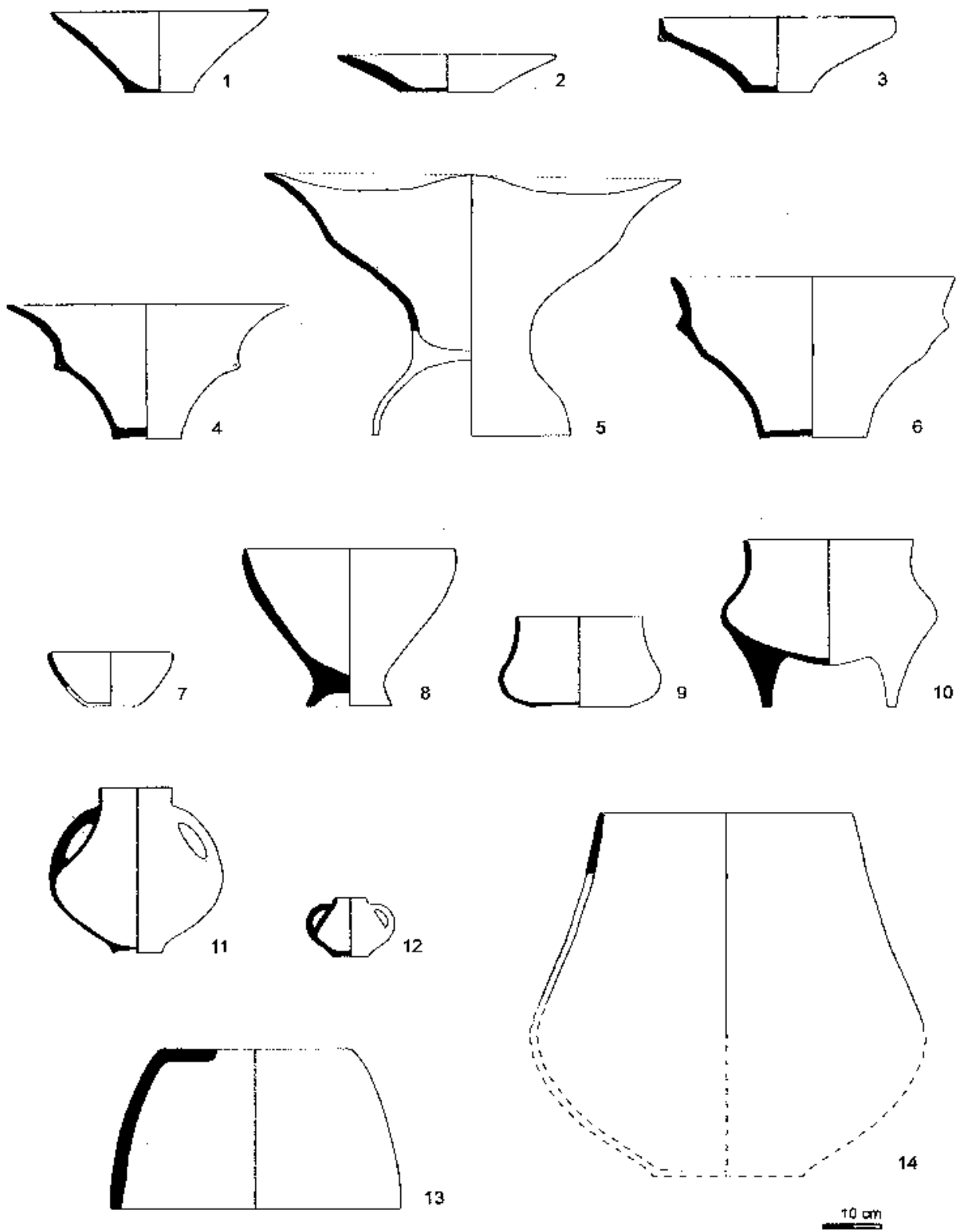

Fig. 2. - Inventaire des formes de récipients « noir sur rouge ». 1-2 : écuelle/plat creux à parois évasées ; 3 : écuelle/plat creux à profil en $S ; 4:$ jatte à profil en $S$, à rebord évasé ; $5:$ jatte à profil en $S$, à rebord évasé, à piédestal ; 6 : jatte à profil en $S$, à ressaut, à rebord évasé ; $7:$ bol hémisphérique ; 8 : bol hémisphérique à pied ; 9 : bol à rebord redressé; 10 : bol à rebord redressé, à quatre pieds ; $11:$ pot à col à deux anses ; 12 : petit pot à deux anses ; 13 : support tronconique ; 14 : jarre (dessin D. Malamidou). 
aller de très faible (0,2-0,4 cm) pour la panse des pots à deux anses (fig. $2: 11$ ), jusqu'à très forte $(2-3 \mathrm{~cm})$ pour les parois des supports et des jarres (fig. $2: 13,14)$. Le décor est riche et couvre la plus grande partie de la surface visible des vases. Les thèmes décoratifs sont complexes, combinant des motifs géométriques linéaires, curvilignes et spiraloïdes. Le décor s'organise dans des zones ou des panneaux denses ou par juxtaposition de motifs pleins libres (fig. 3-6).

Le noyau de ce faciès couvre la partie méridionale de la plaine de Serrès, la plaine de Drama et la vallée de la Piérie du Pangée ${ }^{21}$. Le faciès est également présent dans la vallée du Nestos ${ }^{22}$ et en Thrace méridionale 23 , ainsi que sur l'île de Thasos ${ }^{24}$. Il est attesté en quantités relativement importantes en Macédoine centrale, en particulier dans la zone côtière à l'Ouest de l'embouchure du Strymon et dans le bassin de Langadas ${ }^{25}$. En revanche, il ne se trouve que de façon isolée en Chalcidique ${ }^{26}$, tandis qu'il est extrêmement rare à l'Ouest de l'Axios ${ }^{27}$ (fig. 9, a). Enfin, quelques fragments ont été trouvés sur le site de Pefkakia, en Thessalie ${ }^{28}$, ainsi qu'à Slatino, dans la haute vallée de la Struma en Bulgarie ${ }^{29}$.

L'examen attentif des caractéristiques morpho-stylistiques de ce faciès permet de constater certaines différences entre les productions de la plaine de Drama (site de Dikili Tash), celles de la basse vallée du Strymon et de l'Angitis (Dimitra, Kryonéri) et celles des sites côtiers (Galepsos, Akropotamos). Il s'agit de différences dans la fréquence des motifs

21. Supra, n. 8-11.

22. P. Hellström, op. cit. (supra, n. 11), p. 47 et fig. $25,29 n^{\circ} 17,30 n^{\circ} 24,35 n^{\circ} 132,38 n^{\text {os }} 173-176,40 n^{\circ} 220$, $41 \mathrm{n}^{\text {os }} 245-246$.

23. D. H. FrenCH, loc. cit. (supra, n. 10 [1961]), fig. $6: 11$; G. BAKALAKIS, A. SAKELlariou, op. cit. (supra, n. 14), p. 28, pl. VIb et fig. $10 \mathrm{~b}: 4,32: 1-4$.

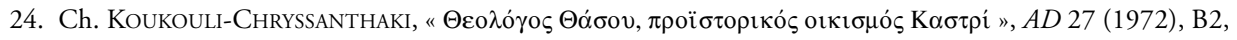

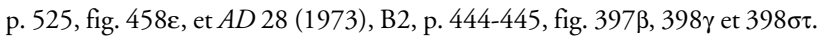

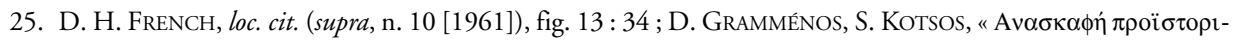

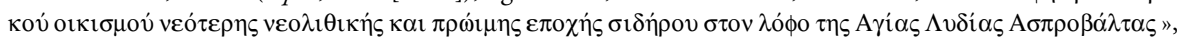
Makedonika 32 (1999-2000), p. 393-441, sp. p. 414, et fig. IX-X ; P. ADAM-VÉLÉNI, M. ViolatZis, P. KarATA-

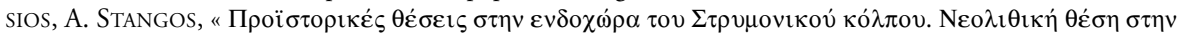

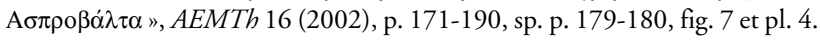

26. D. GRAMMÉNOS, op. cit. (supra, n. 11 [1991]), p. 129.

27. L. STÉPHANI, N. MÉroussis, loc. cit. (supra, n. 13).

28. H.-J. WeIsshaAr, Die deutschen Ausgrabungen auf Pevkakia Magula in Thessalien, I. Das späte Neolithikum und das Chalkolithikum (1989), sp. p. 24 (variantes A et C). Il s'agit de 65 tessons qui proviennent de deux ou trois pots à deux anses.

29. St. CoHAdZIEv, op. cit. (supra, n. 16), p. 43, fig. $110: 1-3,5$, 6, et 111 ; id., «Über die Frage der chronologischen Stellung der bemalten Keramik im Stil “Akropotamos-Galepsos” ", Studia Praehistorica 11-12 (1992), p. 177183 , sp. p. 178 et fig. 1. 


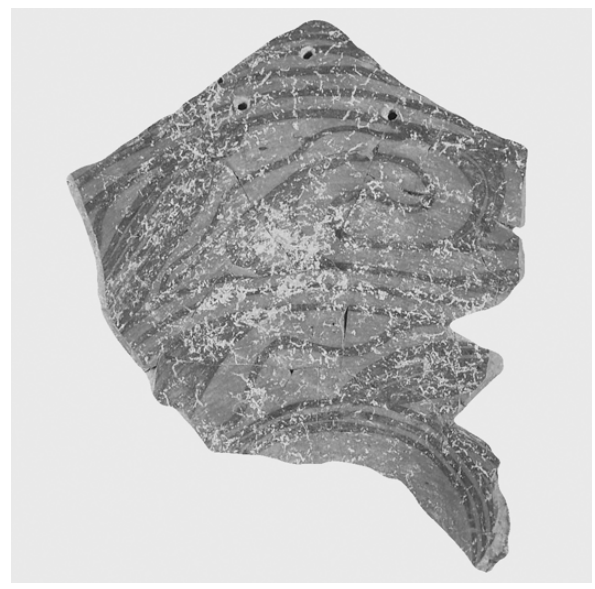

3

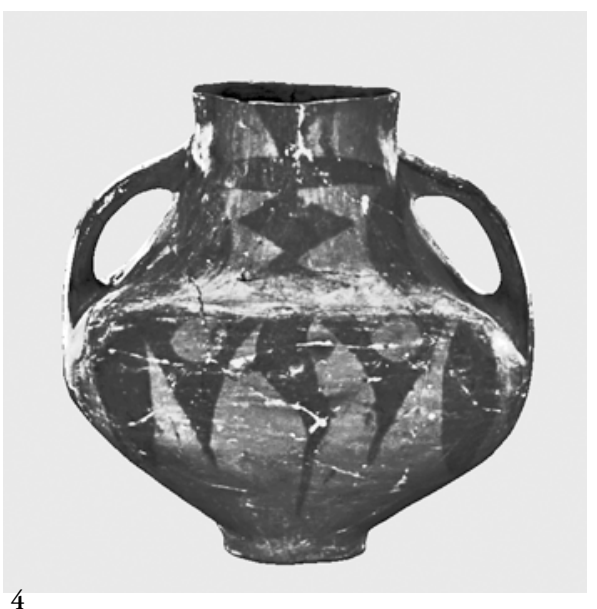

4

Fig. 3. - Faciès 1 : jatte à profil en $S$ à rebord évasé, provenant de Kryonéri (fig. 1, no 28); haut. cons. $25 \mathrm{~cm}$ (cliché St. Stournaras).

Fig. 4. - Faciès 1 : pot à deux anses de Kryonéri (fig. 1, no 28); haut. 26 cm (cliché St. Stournaras).

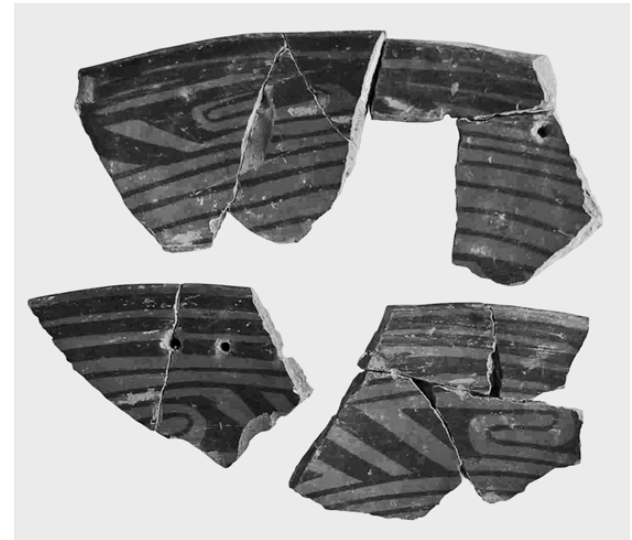

5

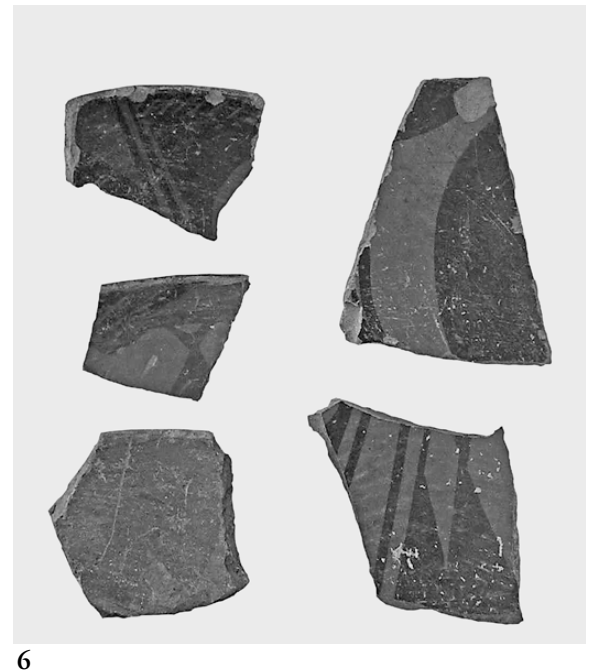

6

Fig. 5. - Faciès 1 , sous-faciès de la plaine de Drama : fragments de jatte à profil en $S$ et à rebord évasé, provenant de Dikili Tash (fig. 1, no 9) (cliché D. Malamidou).

Fig. 6. - Faciès 1, sous-faciès du littoral, à l'Est de l'embouchure du Strymon : fragments de jattes et d'écuelles de Kokkinochori (fig. 1, nº 24) (cliché D. Malamidou). 
décoratifs, l'organisation du décor et son exécution. Ainsi, les vases ouverts provenant de Dikili Tash sont en majorité décorés d'une combinaison de motifs rectilignes et curvilignes (fig. 5), organisés de manière dense et rigoureuse, tandis qu’à Kryonéri la composition du décor est beaucoup moins dense et contient surtout des motifs curvilignes (fig. 3). Par ailleurs, l'on observe une abondance de motifs pleins librement organisés surtout sur les vases provenant des sites du littoral, à l'Est de l'embouchure du Strymon (Galepsos, Akropotamos, Kokkinochori) (fig. 6).

\section{Faciès 2}

Ce faciès se caractérise par une pâte nettement moins fine que celle du faciès 1 , comportant d'abondantes inclusions non plastiques de granulométrie moyenne. La couleur est rouge, rouge-orange ou brun-rouge, tandis qu'en section le cœur se présente assez souvent noirâtre en raison d'une oxydation incomplète. La surface des vases est modérément polie ou lissée, revêtue parfois d'un engobe de la même couleur que la pâte. La peinture est noire ou brune, assez épaisse et couvrante, d'un aspect lisse et mat ${ }^{30}$. L'utilisation du bitume ou d'une autre matière organique noire comme colorant est attestée dans certains cas $^{31}$.

L'inventaire des formes est nettement plus limité que celui du faciès 1 : il s'agit essentiellement de pots à deux anses et de jattes à parois évasées. De plus, l'épaisseur moyenne des parois est plus forte $(0,4$ à $0,9 \mathrm{~cm})$. Les thèmes du décor ne sont pas restituables à cause de l'état fragmentaire du matériel : il couvre en grande partie les surfaces visibles du vase, mais il paraît se limiter à des motifs géométriques linéaires (fig. 7).

Ce faciès n'est représenté que dans la moyenne et haute vallée de la Struma. Il nous est connu essentiellement par les fouilles de Slatino ${ }^{32}$, de Strumsko ${ }^{33}$ et de PromachonTopolnitsa $^{34}$, ainsi que par des prospections de surface dans la même région ${ }^{35}$.

30. L. PernicheVA, «Prehistoric Cultures in the Middle Struma Valley: Neolithic and Eneolithic », in D. W. BAILEY, I. Panayotov (éds), Prehistoric Bulgaria (1995), p. 99-140, sp. p. 128 ; St. Cohadziev, loc. cit. (supra, n. 29),

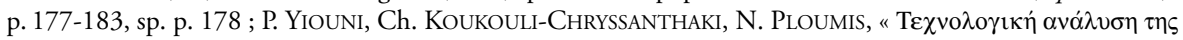

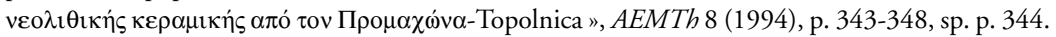

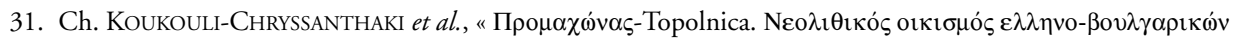

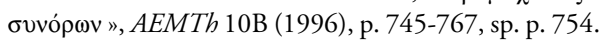

32. St. CoHADZIEV, op. cit. (supra, n. 16).

33. L. PERniCHEVA, loc. cit. (supra, n. 30), fig. 12.

34. Ch. Koukouli-ChryssanthaKi et al., loc. cit. (supra, n. 31).

35. L. Pernicheva, "Prehistory of the Strumesnica Valley ", in J. Sliwa, M. Domaradzki (éds), The Lower Strumesnica Valley in Prehistoric, Ancient and Early Medieval Times (1983), p. 11-33. 


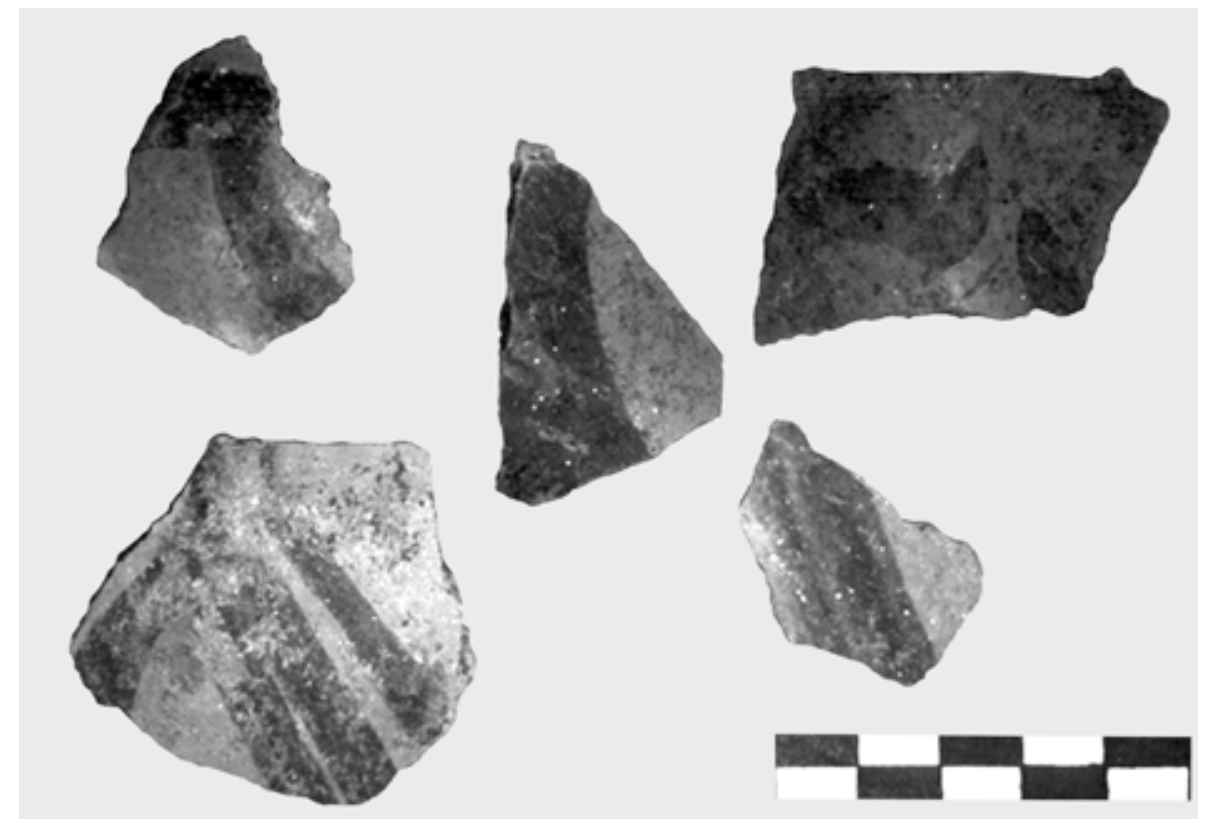

Fig. 7. — Faciès 2 : fragments provenant de Promachon-Topolnitsa (fig. 1, no 105) (cliché D. Malamidou).

\section{Faciès 3}

Les pâtes utilisées pour les poteries de ce faciès sont d'une granulométrie fine à moyenne (moins fine que celle des pâtes du faciès 1 ), avec d'abondants éléments non plastiques visibles à l'œil nu. La couleur de la pâte est brun-rouge, moins souvent rouge ou rouge-orange, tandis que le cœur est souvent noir ou gris, en raison d'une oxydation incomplète. La peinture, de couleur noire ou brun-noir, est peu épaisse, presque transparente, lisse et mate. 

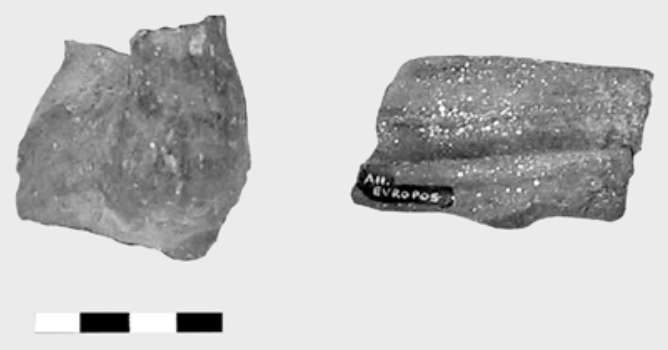

Fig. 8. - Faciès 3 : fragments provenant d'Évropos (fig. 1, no 68) (cliché D. Malamidou).

Les formes des vases sont essentiellement ouvertes (écuelles à parois évasées et à lèvre rentrante et jattes à profil en $\mathrm{S}$ ), mais aussi fermées (pots à deux anses). L'épaisseur des parois varie selon le type de vase, mais elle ne dépasse pas 1-1,5 cm. L'organisation du décor est relativement lâche et comporte des groupes de lignes fines rectilignes ou curvilignes ${ }^{36}$. Le décor peint est parfois combiné à des cannelures ; dans ce cas, la peinture remplit les cannelures, formant des bandes de couleur relativement larges ${ }^{37}$ (fig. 8).

Ce faciès caractérise la Macédoine centrale : il se trouve en Chalcidique, dans la vallée de Vassilika, dans la plaine de Thessalonique, dans le bassin de Langadas ${ }^{38}$ et dans la vallée de l'Axios ${ }^{39}$. Il est également attesté dans la région de Giannitsa ${ }^{40}$. Les fragments d'un vase fermé de Pefkakia peuvent être attribués à ce faciès ${ }^{41}$.

36. G. Mylonas, op. cit. (supra, n. 4), p. 46, pl. 1 et fig. 67-69 ; D. GrammÉNos, St. Kotsos, op. cit. (supra, n. 12 [2002] : Stavroupoli), pl. 13 : a-q; id., op. cit. (supra, n. 12 : Messimériani Toumba), pl. XXXVII : g, XXXVII : q, XI : a.

37. C'est la catégorie céramique 36 à Stavroupoli : D. GrammÉnOs, St. KotSOS, op. cit. (supra, n. 12 : Stavroupoli), p. 36.

38. D. GRAmmÉNOS, op. cit. (supra, n. 11 [1991]), fig. 14 (Drymos).

39. Ibid., fig. 13 (Évropos).

40. P. Chryssostomou, loc. cit. (supra, n. 13 [1996]).

41. Variante B de H.-J. WeISSHAAR, op. cit. (supra, n. 28), p. 24.

BCH 130 (2006) 


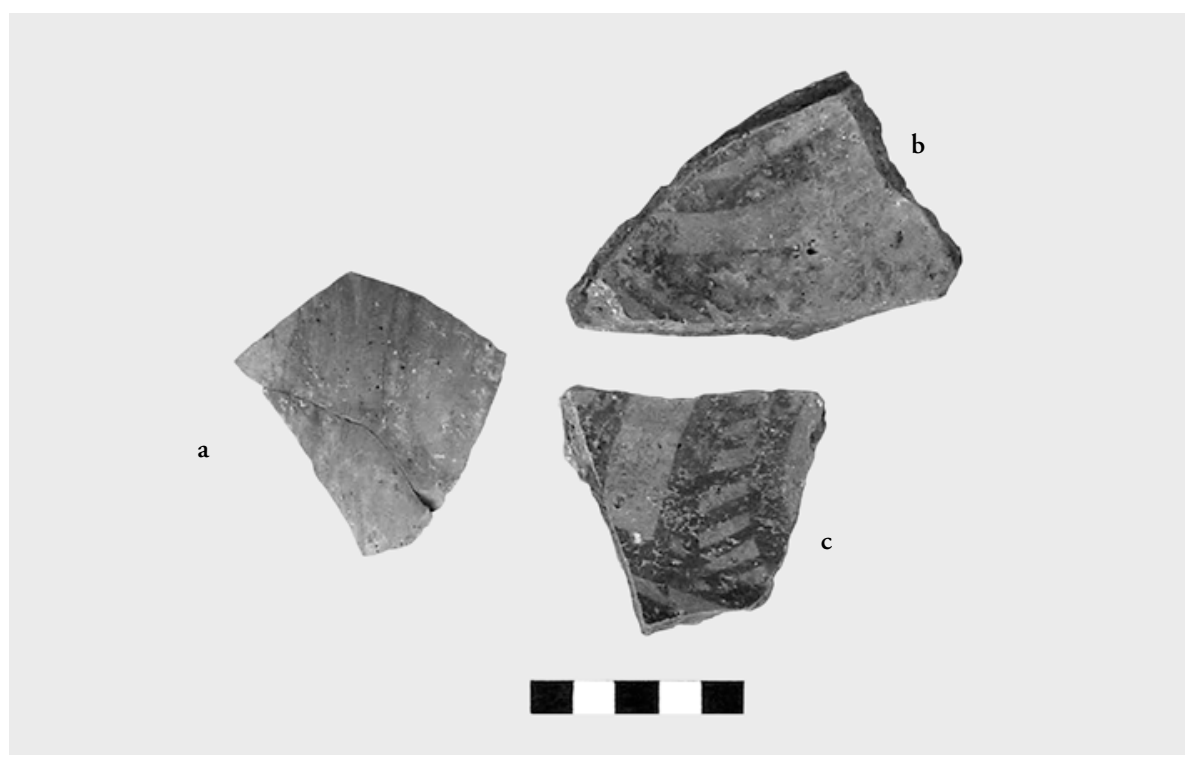

Fig. 9. - Fragments provenant de Polyplatanos (fig. 1, no 83) : a = faciès 1 , b-c = faciès 4 (cliché D. Malamidou).

\section{Faciès 4}

La pâte est à grain moyen, avec un abondant dégraissant visible. Sa couleur est rouge ou brun-orange, plus rarement brun-rouge. En section, le cœur présente une couleur unie ou, parfois, noirâtre. La surface des vases est en général bien polie, apparemment sans engobe. La peinture est noire ou brun-noir et peu épaisse, d'un aspect moins brillant que le reste de la surface. Les formes les plus fréquentes sont ouvertes (écuelles et jattes).

Les motifs décoratifs comportent des groupes de lignes fines organisées en panneaux ou en escalier, ainsi que des méandres rectilignes, des damiers et des spirales, pleins ou hachurés, qui rappellent les motifs de la céramique de Dimini classique (fig. 9, b-c).

Ce faciès caractérise la Macédoine occidentale. Il est particulièrement abondant en Piérie (Makriyalos), dans la vallée de l'Haliakmon et le bassin de Kitrini Limni ${ }^{42}$, ainsi

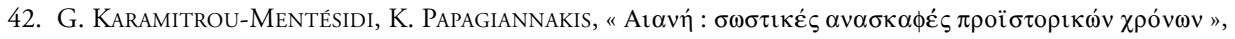
AEMTh 11 (1997), p. 67-80, sp. p. 71. 
que dans la région de Verria et de Giannitsa ${ }^{43}$, tandis qu'il devient plus rare dans les plaines de l'Amyntaion et de Florina. Il est également attesté, dans une moindre mesure, en Macédoine centrale ${ }^{44}$.

\section{Discussion}

L'étude archéologique met en lumière, d'une part, une préférence esthétique commune et durable pour les poteries bicolores en noir et rouge sur l'ensemble de la Grèce du Nord et, d'autre part, l'existence, dans cette même aire géographique, de traditions différentes pour la production de telles poteries.

Leur exécution implique, en effet, certaines normes techniques communes : utilisation de mélanges argileux riches en oxydes de fer et cuisson en atmosphère oxydante afin d'obtenir la couleur rouge du fond, utilisation de peintures à base d'oxyde de manganèse pour obtenir la couleur noire du décor ${ }^{45}$. Ces normes, qui sont en vigueur pendant une période de plusieurs siècles, semblent s'ancrer dans des traditions potières encore plus anciennes, impliquant souvent des matériaux ou des procédés techniques similaires ${ }^{46}$.

Toutefois, il ne s'agit pas d'une production homogène d'un bout de la région à l'autre. La distinction des quatre faciès macroscopiques montre clairement que l'on a affaire au moins à quatre traditions potières, correspondant à des « recettes » différentes. Ces dernières se différencient au niveau de la composition des pâtes, mais aussi au niveau des techniques de finition et de l'emploi des colorants, reflétant alors des variations dans la chaîne opératoire. Le répertoire des formes et l'organisation du décor different également ${ }^{47}$. La variabilité dépend, semble-t-il, des conditions locales d'approvisionnement en matières premières, ainsi que des traditions potières préexistantes ${ }^{48}$.

43. P. Chryssostomou, loc. cit., (supra, n. 13 [1989]), fig. 5 ; L. StépHAni, N. Méroussis, loc. cit., (supra, n. 13

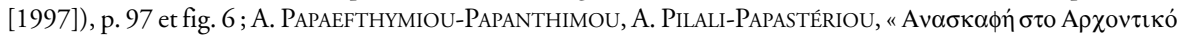

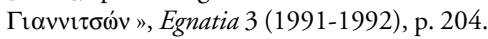

44. D. Gramménos, St. Kotsos, op. cit. (supra, n. 12 : Stavroupoli), pl. XXVI.1.

45. Des matériaux organiques ne sont utilisés que de façon très marginale (supra, n. 31), tandis que les peintures à base d'oxydes de fer ne sont nullement attestées dans ce type de poteries.

46. Z. TsiRTSONI, "Les poteries du début du Néolithique Récent en Macédoine, I. Les types de récipients ", $B C H 124$ (2000), p. 1-55, sp. p. 18.

47. Si l'on tentait de faire la correspondance avec les termes descriptifs utilisés auparavant pour la céramique «noir sur rouge ", le "style d'Olynthe" (W. HeURTLEY, op. cit. [supra, n. 4], p. 74-75) correspondrait à une partie du faciès 3. Les termes «style de Dikili Tash » et "style de Galepsos » et leurs équivalents « style linéaire/style I » et "style libre/style II » (voir, entre autres, J. EvANS et J.-P. DEMOULE, loc. cit. [supra, n. 11]) correspondraient aux différentes variantes du faciès 1 . Il n'existe pas de termes descriptifs particuliers pour les autres faciès.

48. Sur la continuité entre les céramiques " noir sur rouge " du faciès 2 et les céramiques dites de style d' "Akropotamos local » de la phase précédente, voir L. PERNICHEVA, loc. cit. (supra, n. 30), p. 123, 128-129. 
Les modalités de production et de distribution des céramiques « noir sur rouge » se reflètent globalement dans la répartition géographique des quatre faciès. Les zones de répartition sont aisément discernables, malgré quelques recouvrements (fig. 1). Cela indique que la production des récipients et leur diffusion s'organisaient apparemment à une échelle régionale. Les vases ne voyageaient pas loin de leur zone de production, à l'exception de certains cas isolés. C'est surtout le faciès de Macédoine orientale (faciès 1) qui est représenté sur des sites éloignés.

Il est moins facile d'évaluer le rôle de chaque faciès de production dans le contexte socio-économique des sociétés néolithiques. Cependant, l'on remarque que la céramique " noir sur rouge » représente une grande partie de la poterie décorée du Néolithique Récent II en Macédoine orientale, alors qu' elle ne représente qu'une très faible proportion de la poterie décorée de la même époque en Macédoine centrale et occidentale. Cette inégalité concerne aussi bien le matériel ramassé en fouille que celui provenant de collectes de surface. Cela est indicatif du volume et de l'échelle de la production et, par conséquent, de l'importance de cette tradition potière dans chaque zone géographique. Parmi les quatre faciès de production céramique « noir sur rouge », le faciès de Macédoine orientale (faciès 1) paraît correspondre à la tradition potière la plus homogène et la plus dynamique.

Ce faciès est, à l'heure actuelle, le seul à réunir les éléments nécessaires pour une étude plus poussée des modalités de production et de circulation.

D’une part, il est représenté par un matériel archéologique abondant et relativement bien conservé. La plus grande partie de ce matériel provient de fouilles récentes sur un assez grand nombre d'habitats, répartis sur l'ensemble de la zone concernée et présentant des séquences d'occupation plus ou moins longues et bien établies. Il s'agit donc d'objets pour lesquels on dispose d'un bon contexte stratigraphique, chronologique et spatial et qui, en plus, nous étaient accessibles dans de bonnes conditions ${ }^{49}$. En revanche, les faciès 2, 3 et 4 sont représentés par des individus relativement peu nombreux et mal conservés, trouvés souvent en surface ou dans des contextes stratigraphiques incertains, qui ne se prêtent pas à une analyse typologique fine, ni à un échantillonnage raisonné.

49. Outre le matériel très abondant de Kryonéri (fouille de D. Malamidou), on a pu étudier du matériel non publié des sites de Dikili Tash, Kastri, Colline 133-Amphipolis, Giannitsa et Promachon-Topolnica, et réexaminer le matériel déjà publié de Dimitra, Sitagri, Polystylo, Akropotamos, Paradisos et Pefkakia. Nous remercions tous les responsables de nous avoir permis d'étudier de près ce matériel : P. Chryssostomou, J.-P. Demoule, D. Gramménos, P. Hellström, Ch. Koukouli-Chryssanthaki, C. Renfrew, R. Treuil et H.-J. Weisshaar. 
D’autre part, la Macédoine orientale, qui est la zone de répartition principale de ce faciès, et tout particulièrement la plaine de Drama, constitue l'une des régions de Grèce du Nord dont la géologie a été le mieux étudiée ${ }^{50}$. Cela est vrai notamment pour les formations superficielles de la fin du Pléistocène et de l'Holocène, dans lesquelles il faut rechercher les gisements potentiels d'argiles ${ }^{51}$.

Pour ces raisons, nous avons décidé de nous concentrer sur l'étude approfondie du seul faciès 1 . Il s'agissait d'étudier en détail la composition des pâtes céramiques représentées par ce faciès, puis d'examiner la possibilité de les associer à des sources de matières premières identifiées à cette fin. Cette enquête pourrait servir de modèle ou de base pour des démarches analogues sur les autres faciès, voire sur d'autres productions céramiques.

\section{APPROCHE ANALYTIQUE ET GROUPES CHIMIQUES DANS LE FACIÈS 1}

Comme on l'a déjà noté (supra, p. 00), l'étude pétrographique n'est pas d'un grand secours dans le cas de céramiques aussi fines que les poteries "noir sur rouge ", notamment celles du faciès $1^{52}$. Dans ces conditions, seule l'analyse chimique peut fournir des renseignements sur la composition des pâtes, permettant ainsi de distinguer des mélanges utilisant des matériaux d'origine géologique différente.

\section{L'échantillonnage}

198 échantillons, provenant de 16 sites du NR II, ont fait l'objet d'une analyse par activation neutronique (NAA).

La très grande majorité (194 échantillons) provient de sites de Macédoine orientale, depuis le Strymon jusqu'à l'embouchure du Nestos, l'île de Thasos comprise ; sont représentés 14 sites : Akropotamos, Colline 133-Amphipolis, Dikili Tash, Dimitra, Fidokoryfi,

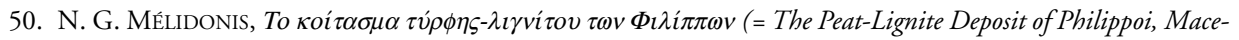
donia, Greece) (1969).

51. L. LESPEZ, L'évolution des modelés et des paysages de la plaine de Drama et de ses bordures montagneuses (Macédoine orientale, Grèce) au cours de l'Holocène, thèse de doctorat, université de Clermont-Ferrand (1999) ; id., "L'évolution des paysages du Néolithique à la période ottomane dans la plaine de Philippes-Drama ", in Dikili Tash, village préhistorique de Macédoine orientale. Recherches franco-helléniques (1986-2001), (2008), p. 21-394.

52. Sa composition minéralogique présente une association constante d'inclusions : mica, quartz, feldspaths, traces d'oxydes de fer. Toutes les inclusions sont très fines $(<20 \mathrm{~mm})$ et appartiennent, très probablement, à la portion argileuse de la pâte : cf. supra, p. 00 et n. 19. 


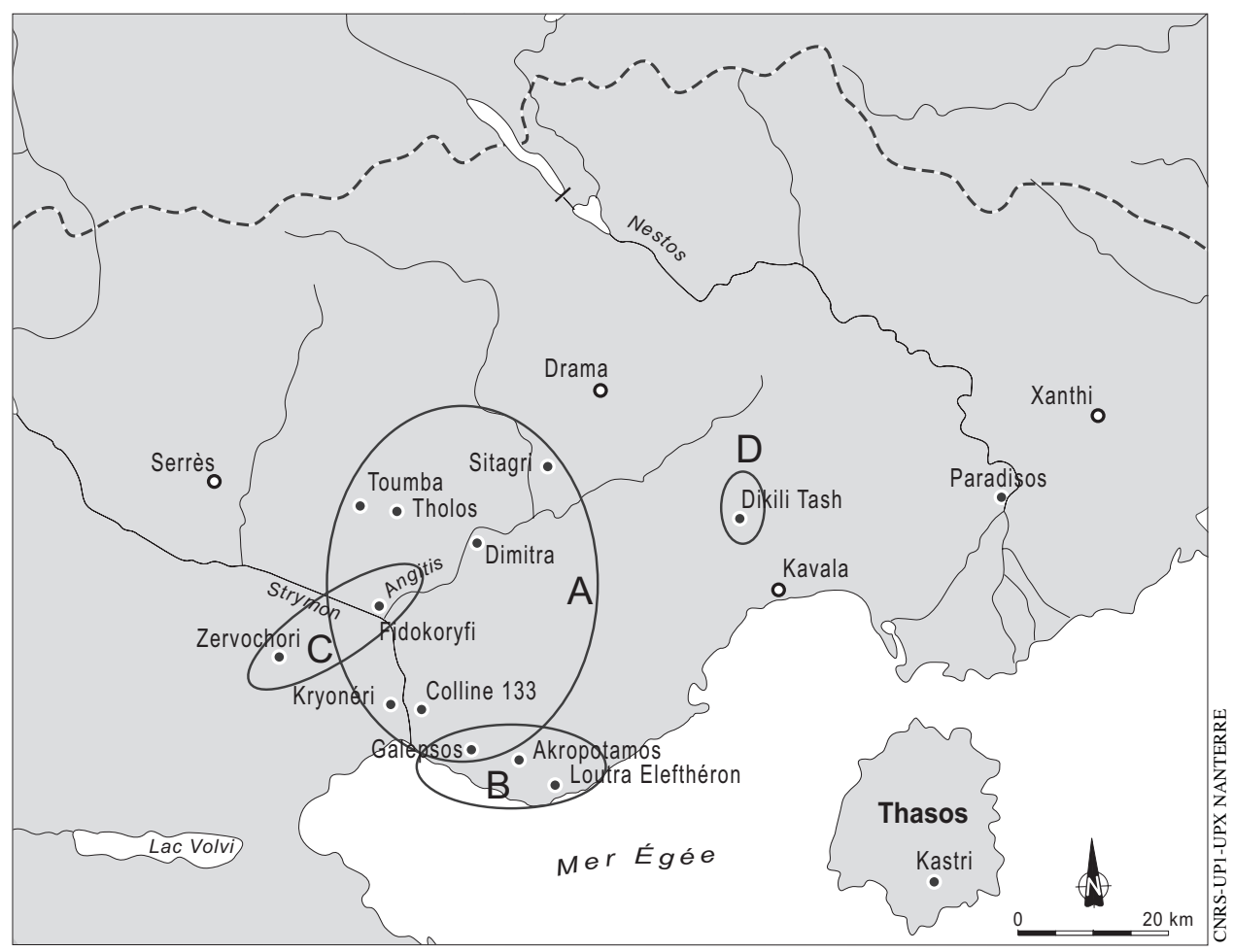

(C) 2002-100 Cartographie Catherine FINETIN

Maison René Ginouvès - Archéologie \& Ethnologie

Fig. 10. - Sites de la Macédoine orientale ayant fourni des échantillons céramiques pour des analyses (les cercles dessinent la répartition dans l'espace des types de poteries « noir sur rouge » A à D).

Galepsos, Kastri, Kryonéri, Loutra Élefthéron, Paradisos, Sitagri, Tholos, Toumba et Zervochori (fig. 1, nos 23, 27, 9, 30, 29, 25, 7, 28, 22, 5, 16, 32, 33, 39, et fig. 10). Trois échantillons proviennent de Pefkakia, en Thessalie (no 104), et le dernier vient de Giannitsa $B$, en Macédoine occidentale (no 78).

En réalité, seuls 172 de ces échantillons appartiennent à des poteries "noir sur rouge "; 16 échantillons appartiennent à des vases sans décor, mais fabriqués dans une pâte macroscopiquement analogue à celle des poteries " noir sur rouge ", et 9 autres à des céramiques 


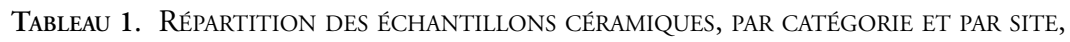
DANS LES DOUZE GROUPES DE COMPOSITION CHIMIQUE

\begin{tabular}{l|r|r|r|r|r|r|r|r|r|r|r|r|r|r} 
Vases « noir sur rouge " & G1 & G2 & G3 & G4 & G5 & G6 & G7 & G8 & G9 & G10 & G11 & G12 & ind. & total \\
\hline \hline Kryonéri & 14 & 21 & & 2 & 1 & 6 & & 1 & 1 & 1 & & & & 47 \\
\hline Colline 133 & 3 & 2 & 1 & 1 & & 3 & & & & & & & & 10 \\
\hline Dimitra & 6 & 9 & 1 & & & 2 & & & & & & & & 18 \\
\hline Toumba & 2 & 5 & & & 1 & & 1 & & & & & & 1 & 10 \\
\hline Tholos & 5 & & & 2 & & 1 & & & & & & & & 8 \\
\hline Sitagri & 6 & 2 & & & & 1 & & & & & & & & 9 \\
\hline Fidokoryfi & 1 & 1 & & & 1 & & & & & & 4 & & 1 & 8 \\
\hline Zervochori & & 1 & & & 1 & & & & & & 2 & & & 4 \\
\hline Akropotamos & 1 & & 1 & & & 2 & & 5 & 1 & & & & & 10 \\
\hline L. Élefthéron & & 1 & & & & & & 9 & & & & & & 10 \\
\hline Galepsos & & 3 & & & & 4 & & 3 & & & & & & 10 \\
\hline Dikili Tash & 2 & & & & & 1 & 1 & & & & & 5 & & 9 \\
\hline Paradisos & & & 1 & & & 2 & 1 & 1 & & & & & & 5 \\
\hline Kastri, Thasos & 1 & 3 & & & & 3 & 1 & 1 & 1 & & & & & 10 \\
\hline Pefkakia & & 2 & & & & 1 & & & & & & & & 3 \\
\hline Giannitsa B & & & & 1 & & & & & & & & & & 1 \\
\hline
\end{tabular}

Vases sans décor

\begin{tabular}{l|r|r|r|r|r|r|r|r|r|r|r|r|r|r}
\hline & G1 & G2 & G3 & G4 & G5 & G6 & G7 & G8 & G9 & G10 & G11 & G12 & ind. & total \\
\hline \hline Kryonéri & 1 & 3 & 1 & & 2 & 2 & & & & & & & 1 & 10 \\
\hline Dimitra & 2 & & & & & & & 1 & & & & & & 3 \\
\hline Sitagroi & & & & & & 1 & & & & & & & & 1 \\
\hline Dikili Tash & & & & & & & & 1 & & & & 1 & & 2 \\
\hline
\end{tabular}

Vases " brun sur crème "

\begin{tabular}{l|c|c|c|c|c|c|c|c|c|c|c|c|c|c}
\hline & G1 & G2 & G3 & G4 & G5 & G6 & G7 & G8 & G9 & G10 & G11 & G12 & ind. & total \\
\hline \hline Kryonéri & & & & & & 1 & & & & 8 & & & & 9 \\
\hline & & & & & & 1 & & & & 8 & & & & 9 \\
\hline
\end{tabular}

Vase au graphite

\begin{tabular}{|c|c|c|c|c|c|c|c|c|c|c|c|c|c|c|}
\hline & G1 & G2 & G3 & G4 & G5 & G6 & G7 & G8 & G9 & G10 & G11 & G12 & ind. & \\
\hline \multirow[t]{2}{*}{ Kryonéri } & & & & & 1 & & & & & & & & & 1 \\
\hline & & & & & 1 & & & & & & & & & 1 \\
\hline
\end{tabular}


à décor peint avec une peinture brun-gris sur fond crème ${ }^{53}$. Enfin, un échantillon provient d'un vase décoré au graphite, mais dont la pâte, cuite noire, présente une texture analogue à celle des céramiques " noir sur rouge ${ }^{54}$ "(tableau 1$)$. Avec ces comparaisons, on voulait examiner la relation possible, sur le plan technologique, entre les céramiques « noir sur rouge » et des céramiques contemporaines plus ou moins proches macroscopiquement.

\section{La méthode d'analyse}

La méthode utilisée était l'activation neutronique (NAA). Une portion de chaque échantillon a été pulvérisée, puis laissée à sécher durant la nuit à la température de $120{ }^{\circ} \mathrm{C}$. Environ $130 \mathrm{mg}$ de chaque échantillon ont été prélevés et placés dans des tubes en polyéthylène, que l'on a ensuite fermés hermétiquement. La même procédure a été suivie pour la préparation des échantillons de référence : un échantillon de sédiment (International Atomic Energy Agency SOIL-7) et un échantillon d'argile de Pikermi, pris dans la base de données du centre de recherches Démokritos. L’on a procédé ensuite à l'irradiation des échantillons, par groupes de dix (8 échantillons céramiques plus les deux échantillons de référence) dans le réacteur atomique du centre, au moyen d'un flux thermal de neutrons de $4 \times 10^{13} \mathrm{n} \cdot \mathrm{cm}^{-2} \cdot \mathrm{s}^{-1}$. Après sept jours, on a mesuré leurs teneurs en une dizaine d'éléments chimiques : samarium $(\mathrm{Sm})$, lutétium $(\mathrm{Lu})$, uranium $(\mathrm{U})$, ytterbium $(\mathrm{Yb})$, arsenic $(\mathrm{As})$, antimoine $(\mathrm{Sb})$, calcium $(\mathrm{Ca})$, sodium $(\mathrm{Na})$, potassium $(\mathrm{K})$, lanthane $(\mathrm{La})$; vingt jours plus tard, on a mesuré, en plus, leurs teneurs en cérium (Ce), thorium (Th), chrome $(\mathrm{Cr})$, hafnium (Hf), zirconium $(\mathrm{Zr})$, césium $(\mathrm{Cs})$, terbium $(\mathrm{Tb})$, scandium $(\mathrm{Sc})$, rubidium $(\mathrm{Rb})$, fer $(\mathrm{Fe})$, zinc $(\mathrm{Zn})$, tantale $(\mathrm{Ta})$, cobalt $(\mathrm{Co})$ et europium $(\mathrm{Eu})$.

Le taux de précision de l'installation, exprimé comme l'écart-type de la moyenne des dix valeurs, était inférieur à $6 \%$ pour tous les éléments traces à l'exception de U, Ca et $\mathrm{Tb}^{55}$. L'exactitude a été testée par rapport à un échantillon de référence (National Institute of Standards and Technology Montana Soil) : elle était de l'ordre de $9 \%$ ou moins pour tous les éléments traces, sauf $\mathrm{Ce}, \mathrm{Cr}$, U et $\mathrm{Yb}$ (mais les valeurs du NIST pour ces éléments ne sont de toute façon pas certifiées).

53. Les céramiques de ce type se trouvent régulièrement associées aux céramiques « noir sur rouge » en Macédoine orientale et centrale et partagent avec elles de nombreux traits technologiques et morphologiques, ainsi que des éléments décoratifs.

54. Cela est totalement inhabituel pour une céramique de ce type. En effet, les céramiques à décor peint au graphite de cette époque sont systématiquement faites d'une pâte moyennement à très riche en inclusions minérales, parfois assez volumineuses : E. GARDNER, loc. cit. (supra, n. 19), p. 290 ; L.-C. COURTOIS, loc. cit. (supra, n. 19), p. 10.

55. A. Tsolakidou, V. Kilikoglou, « Comparative Analysis of Ancient Ceramics by Neutron Activation Analysis, Inductively Coupled Plasma-Optical-emission Spectrometry, Inductively Coupled Plasma-Mass Spectrometry, and X-ray Fluorescence ", Analytical and Bioanalytical Chemistry 374 (2002), p. 566-572. 
Les mesures brutes ont été exprimées en proportions par rapport à l'élément trace scandium $(\mathrm{Sc})$. Cette transformation a été jugée nécessaire afin de compenser la variabilité chimique engendrée par la présence des inclusions non plastiques dans la pâte céramique $^{56}$. Le traitement statistique de ces valeurs a permis de former des groupes, selon les distances entre les différentes teneurs (classification ascendante hiérarchique selon le calcul des distances euclidiennes). Ensuite, on a calculé la moyenne, puis l'écarttype $(1 \sigma)$ de chaque élément. La pertinence des groupes a été établie d'après la hauteur de l'écart-type et les différences, en valeurs absolues, entre les moyennes.

\section{Les résultats}

L'on a identifié douze groupes de composition chimique, présentant chacun une homogénéité interne exceptionnelle, qui s'exprime par les très faibles écarts-types de tous les éléments dans tous les groupes (tableau 2). Des écarts-types aussi faibles sont extrêmement rares dans les céramiques néolithiques. En effet, on ne rencontre des groupes aussi serrés que dans des productions céramiques standardisées et à grande échelle57. Plus généralement, à l'exception des échantillons à décor peint "brun sur crème » (groupe 10), les valeurs obtenues pour les différents éléments ne varient pas énormément d'un groupe chimique à l'autre. Cette relative homogénéité est encore plus soulignée par l'hétérogénéité que présentent les compositions des échantillons d'argiles locales (cf. infra, p. 00).

Les douze groupes de composition chimique peuvent être regroupés en cinq types distincts : quatre types $(\mathrm{A}, \mathrm{B}, \mathrm{C}$ et $\mathrm{D})$ correspondent à des argiles utilisées pour la fabrication des poteries à décor peint «noir sur rouge » et de celles sans décor ; le cinquième type $(\mathrm{E})$ correspond aux poteries à décor peint «brun sur crème ».

Les deux premiers types de pâtes (types A et B) comportent un nombre d'échantillons statistiquement significatif. La définition des trois derniers (types $\mathrm{C}, \mathrm{D}$ et $\mathrm{E}$ ) s'appuie sur un nombre d'échantillons relativement faible; toutefois, leur originalité chimique et leur répartition géographique particulière les rendent significatifs pour notre étude.

56. J. Buxeda I Garrigos, "Alteration and Contamination of Archaeological Ceramics : the Perturbation Problem ", JournArchSc 26 (1999), p. 295-313.

57. A. Hein, H. Mommsen, J. Maran, «Element Concentration Distributions and most Discriminating Elements for Provenancing by Neutron Activation Analysis of Ceramics from Bronze Age Sites in Greece ", JournArchSc 26 (1999), p. 1053-1058. 


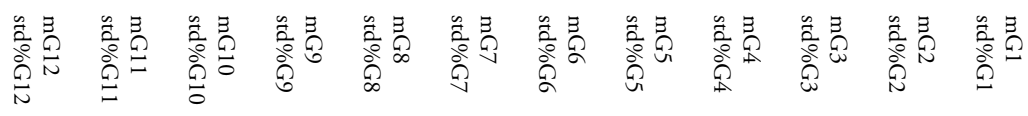

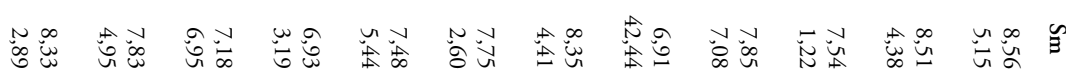

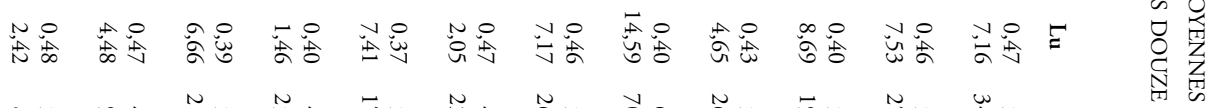

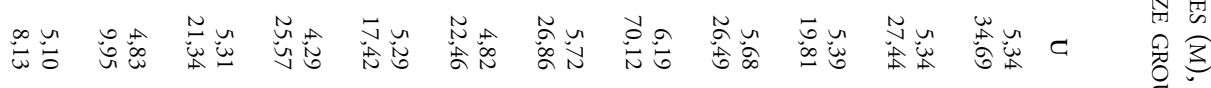

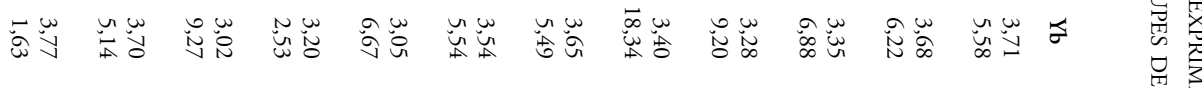

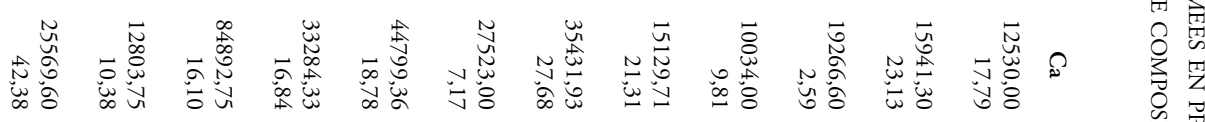

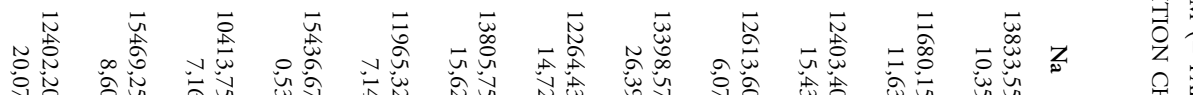
等

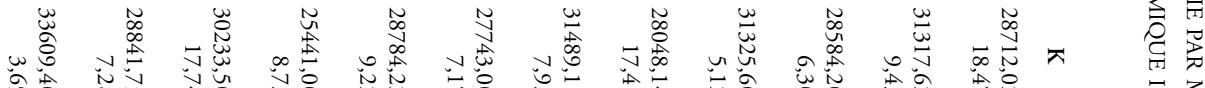

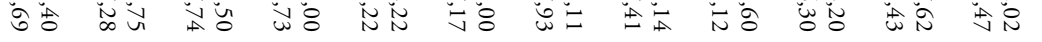

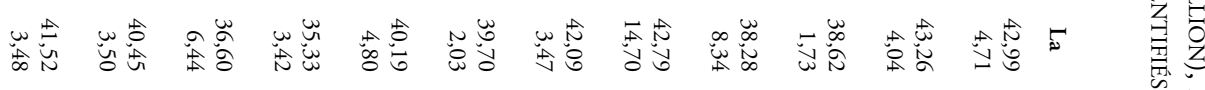

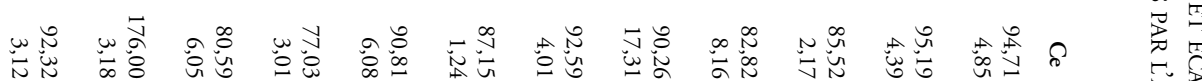

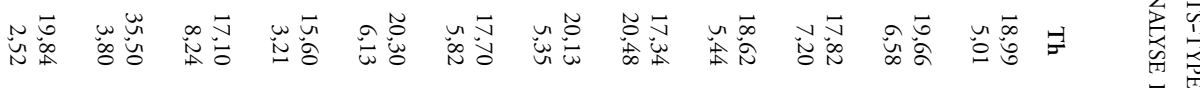

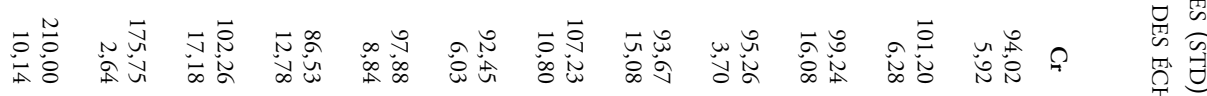

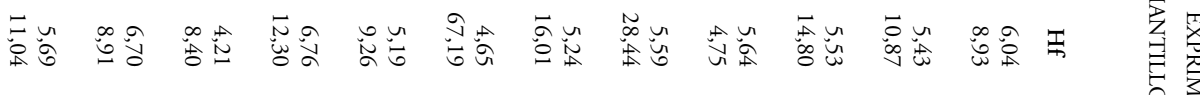

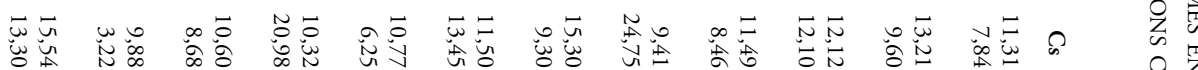

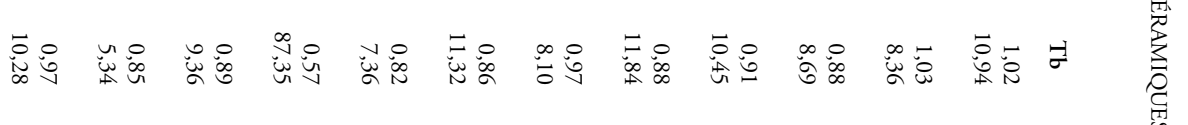

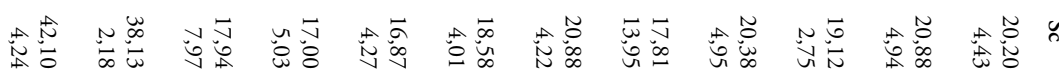

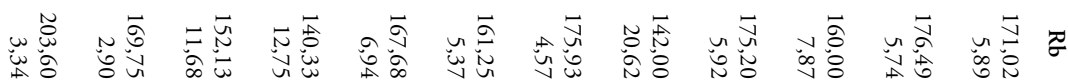

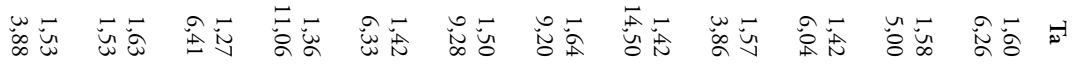

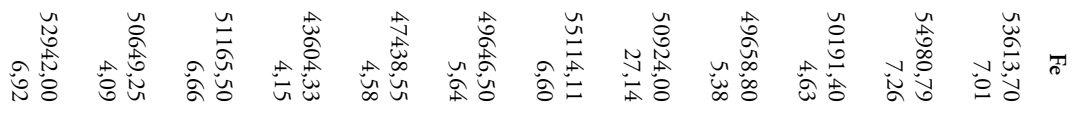

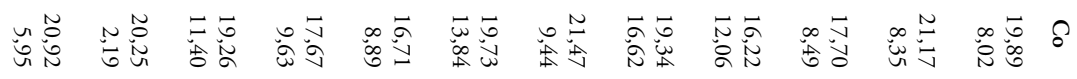

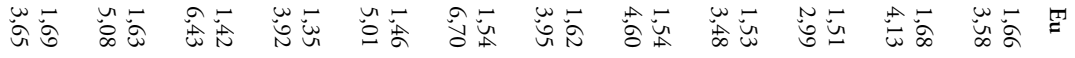


Type A (groupes 1 à 6)

Ce type de pâte comporte 145 échantillons au total. Il est dominé par les groupes chimiques 1 et 2 (comportant 44 et 53 échantillons respectivement). Ces deux groupes sont les plus homogènes dans leur composition. Ils présentent des écarts-types très faibles (inférieurs à $10 \%$ ) pour tous les éléments traces et pour le fer $(\mathrm{Fe})$. Même les éléments alcalins $(\mathrm{Na}, \mathrm{K}, \mathrm{Cs})$, qui sont généralement susceptibles de varier considérablement, présentent des écarts-types relativement faibles (environ 9-18\%). Les seuls éléments qui présentent une plus grande variabilité sont le calcium (17-23\%) et l'uranium (27-35\%). Pour ce dernier, cela s'explique par la teneur particulièrement élevée des échantillons de Toumba. De fait, les deux groupes 1 et 2 peuvent être considérés comme formant un seul ensemble. La majorité des échantillons de Kryonéri (tableau 3), de la Colline 133, de Tholos, de Toumba, de Dimitra, de Sitagri et de Pefkakia appartiennent à cet ensemble, tandis que les autres sites y sont représentés dans des proportions beaucoup plus faibles.

Les groupes 3 à 6 peuvent être considérés comme des variantes des groupes principaux 1 et 2 . Les groupes 3,4 , et 5 se différencient des groupes 1 et 2 par des variations mineures et concernent peu d'échantillons (18), assez dispersés sur le plan géographique. Le groupe 6 est caractérisé par une teneur plus importante en calcium (Ca). Il comporte 30 échantillons, eux aussi dispersés sur presque tous les sites étudiés.

Type B (groupe 8)

Le type $B$ se distingue du type A par sa teneur en calcium $(\mathrm{Ca})$ relativement élevée (autour de $4,5 \%$ contre moins de $2 \%$ pour la plupart des échantillons du type A), ainsi que par des teneurs plus faibles en scandium $(\mathrm{Sc})$, en fer $(\mathrm{Fe})$ et en cobalt (Co) (tableau 4). Ce groupe comporte 22 échantillons provenant essentiellement de Loutra Élefthéron (9 échantillons), d'Akropotamos (5) (tableau 5) et de Galepsos (3).

Tableaux 3, 5, 6, 7. Répartition dans les groupes de composition chimique des échantillons céramiques 3. Kryonéri : prédominance des groupes du type $\mathrm{A}$ (groupes 1 à 6 ).

5. Akropotamos : prédominance du type B (groupe 8).

6. Fidokoryfi : prédominance du type $\mathrm{C}$ (groupe 11).

7. Dikili Tash : prédominance du type D (groupe 12).

Tableaux 4, 8, 9. Diagrammes binaires des échantillons céramiques 4. Types A et B. PC1, comportant les éléments Sc, Sm et Eu, représente $22 \%$ de la variabilité totale, tandis que PC2, comportant $\mathrm{Na}$, Hf, Th et $\mathrm{Cr}$, représente $13 \%$.

8. Types A, C et D. PC1, comportant les éléments $\mathrm{Eu}, \mathrm{Rb}$ et Cs, représente $14 \%$ de la variabilité totale ; PC2, comportant $\mathrm{Ce}, \mathrm{Th}, \mathrm{Cr}$ et $\mathrm{Sc}$, représente $13 \%$.

9. Types B, C et D. PC1, comportant les éléments Sc, Cr et $\mathrm{Yb}$, représente $26 \%$ de la variabilité totale; PC2, comportant $\mathrm{Na}$, Th, Cs et Hf, représente $14 \%$.

BCH 130 (2006) 

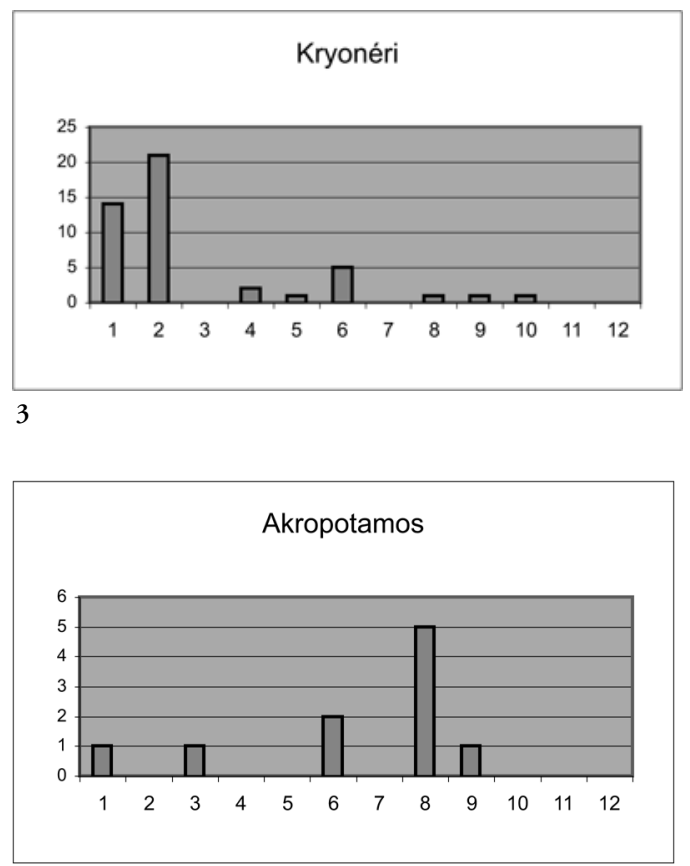

5
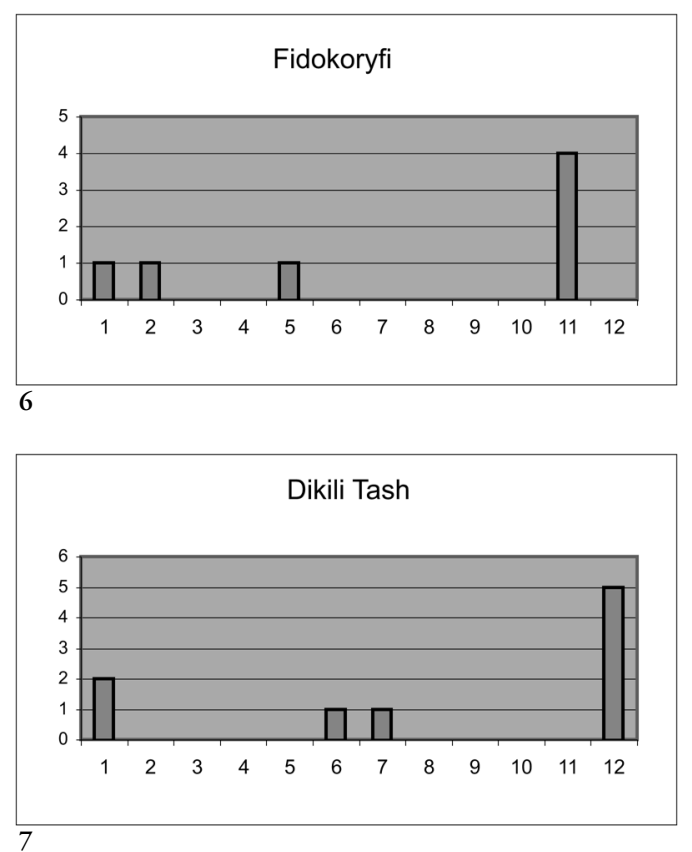
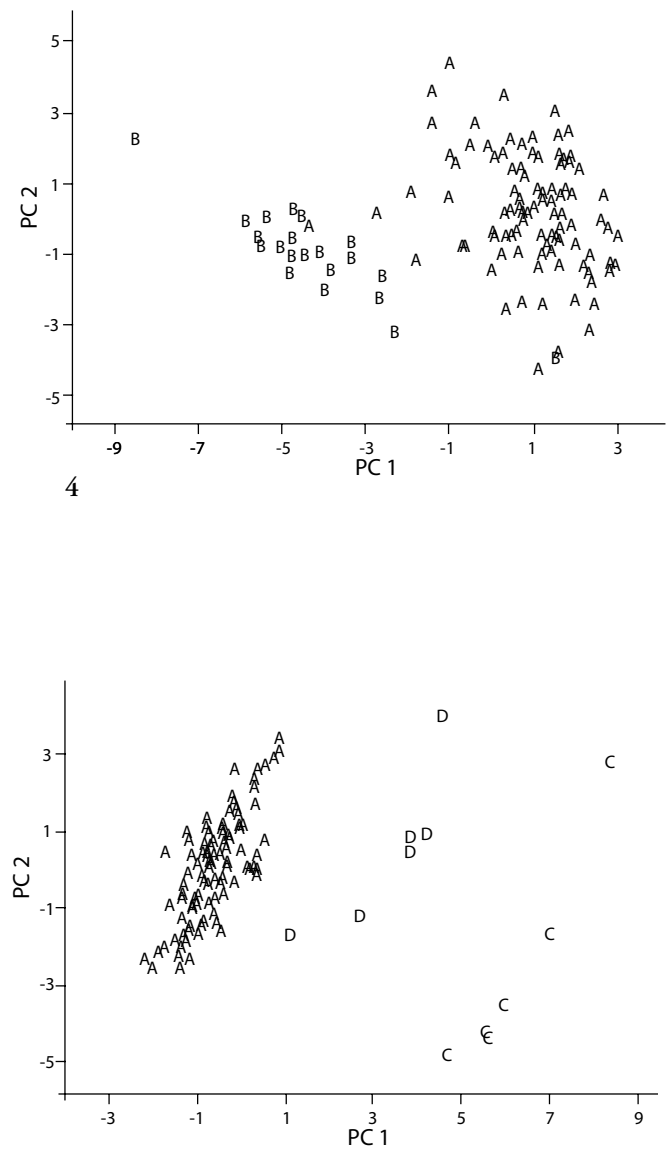

8

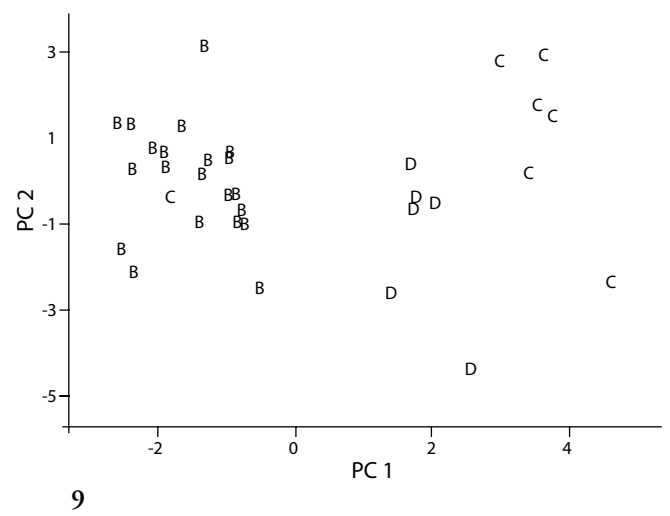

BCH 130 (2006) 
Type C (groupe 11)

Le type $\mathrm{C}$ se caractérise par des teneurs plus élevées en thorium (Th), en chrome (Cr) et en scandium (Sc). Il forme un groupe cohérent, mais comporte peu d'échantillons (6) provenant des seuls sites de Zervochori et de Fidokoryfi (tableau 6).

Type D (groupe 12)

Le type D ne comporte que 6 échantillons provenant de Dikili Tash (tableau 7). Il se distingue par des teneurs particulièrement élevées en chrome $(\mathrm{Cr})$, en rubidium $(\mathrm{Rb})$ et surtout en scandium $(\mathrm{Sc})$, qui atteint le double des échantillons des types $\mathrm{A}$ et $\mathrm{B}$ (tableaux 8 et 9). Il présente par ailleurs une forte variabilité de la teneur en calcium (Ca).

\section{Type E (groupe 10)}

Ce type de pâte est exceptionnellement riche en calcium (Ca). Sa teneur atteint en moyenne environ $8,5 \%$, alors qu'elle ne dépasse dans aucun autre type les $4,5 \%$. La quasi-totalité des échantillons (8 sur 9) provient de céramiques «brun sur beige ». Cela confirme l'utilisation d'une pâte différente pour la fabrication de cette céramique, comme le suggérait déjà l'étude macroscopique ${ }^{58}$. Seul un échantillon "noir sur rouge » appartient à ce type ; sa particularité avait déjà été repérée macroscopiquement, puisqu'il s'agit d'un vase fabriqué avec une argile blanchâtre revêtue d'un engobe rouge.

Dix échantillons (quatre formant le groupe chimique 7, trois formant le groupe 9 et trois échantillons isolés) ne se rangent dans aucun des cinq types.

\section{Conclusions sur la caractérisation des pâtes}

Un examen de la localisation des échantillons appartenant aux quatre types de céramiques " noir sur rouge " (types A, B, C, D) révèle une organisation spatiale claire. En effet, les différents types de pâtes correspondent à des zones géographiques distinctes (fig. 10) :

- le type A, diffusé dans l'ensemble de l'espace étudié, correspond à la majorité des échantillons prélevés dans les sites de la basse vallée du Strymon (Colline 133, Kryonéri, Tholos, Toumba) et de la vallée de l'Angitis (Dimitra, Sitagri);

- le type B correspond aux sites proches du littoral, à l'Est de l'embouchure du Strymon (Akropotamos, Galepsos, Loutra Élefthéron);

58. Supra, n. 53.

BCH 130 (2006) 
- le type C ne se retrouve que sur les sites de Fidokoryfi et de Zervochori, soit au centre-Ouest du secteur étudié ;

- enfin, le type D est réservé au site de Dikili Tash, aux marges orientales de la plaine de Drama.

Cette configuration suggère l'existence d'au moins quatre espaces de production des céramiques « noir sur rouge ", correspondant à l'utilisation de quatre recettes impliquant des matières premières différentes. Cela ne veut pas dire que l'on a affaire à quatre " ateliers ", puisque, au sein de chaque espace, la production a pu s'appuyer sur un seul centre de production (lui-même comportant plusieurs ateliers) ou sur plusieurs exploitant les mêmes ressources. Mais on a quatre secteurs d'approvisionnement, chacun étant caractérisé par la présence et/ou la proportion d'éléments d'une composition chimique précise. Au sein de chaque espace de production, il existe encore des sous-groupes de composition, fait qui peut s'expliquer par des variations locales dans les sources des matériaux, toutefois très comparables et vraisemblablement voisines sur le plan géographique. En effet, l'homogénéité des groupes chimiques formant les principaux types de pâte ne laisse aucun doute quant à l'origine géologique commune de ces éléments : autrement dit, il paraît certain que les ingrédients de toutes les pâtes céramiques, par exemple, du type A proviennent des mêmes sources de matières premières (mêmes carrières).

Les céramiques des sites les plus éloignés (Paradisos, Kastri, Pefkakia, Giannitsa) n’ont pas de caractéristiques propres. La grande majorité des échantillons provenant de ces sites se classe dans le type de pâte A. Un faible nombre d'échantillons de Kastri et de Paradisos appartient au type B. Cela signifie très probablement que ces céramiques ont voyagé, pour elles-mêmes ou pour leur contenu, depuis leurs lieux de production en Macédoine orientale jusqu'aux lieux de leur découverte.

En outre, les analyses montrent que les mêmes pâtes céramiques ont été utilisées pour la fabrication de vases sans décor de grandes dimensions. Ce point est important pour ce qui concerne l'organisation de la production des céramiques en général. Il apparaît alors que, dans certains " ateliers », les potiers utilisaient des matériaux identiques pour les vases décorés et pour ceux sans décor. 


\section{RECHERCHE DES RESSOURCES EN ARGILE DU FACIÈS 1}

\section{État de la question}

Aucun des sites néolithiques connus jusqu'à présent en Macédoine orientale n’a livré des déchets de fabrication de céramique (" noir sur rouge » ou autre), ni de dispositifs que l'on pourrait identifier avec certitude comme des fours de potier ${ }^{59}$. Nous ne connaissons donc pas d'ateliers de potier, au sens propre du terme.

Pourtant, on sait que des terres argileuses ont été couramment utilisées dans la région depuis au moins le début du Néolithique Récent (c'est-à-dire à partir de la deuxième moitié du VIe millénaire av. J.-C.) et jusqu'à nos jours, pour le façonnage de poteries, mais aussi pour la construction de murs et d'aménagements dans les maisons (fours, banquettes, silos), ainsi que pour la fabrication d'outils et de figurines. En plus, il apparaît que la sélection des terres se faisait selon des critères plus ou moins précis, en fonction de l'usage prévu ${ }^{60}$. Cela présuppose une bonne connaissance des ressources naturelles et des qualités des différents matériaux, ainsi qu'une capacité à exploiter ces derniers pour satisfaire des besoins techniques et/ou des demandes esthétiques sur un certain nombre d'objets : plasticité, porosité, résistance au feu, mais aussi onctuosité au toucher, coloration précise, etc.

Nos connaissances sur les gisement d'argile actuellement présents dans la région s'appuient, pour l'essentiel, sur des cartes géologiques à grande échelle, tandis que des prospections géomorphologiques ciblées pour des études de provenance de matériaux (essentiellement des roches) sont très rares. Il a fallu donc entreprendre une prospection systématique afin de chercher des sources d'argile susceptibles d'avoir été utilisées pour les céramiques " noir sur rouge ».

59. À l'exception peut-être d'une structure mise au jour à Kryonéri : D. MALAMIDOU, loc. cit. (supra, n. 18). Les restes d'un supposé four de potier dans un niveau du début du Néolithique Récent à Dikili Tash appartiennent, très probablement, en réalité à une plate-forme attenante à un four domestique : Z. TSIRTSONI, «Les poteries du début du Néolithique Récent en Macédoine, 2. Les fonctions des récipients ", BCH 125 (2001), p. 10.

60. Une telle gestion raisonnée des matières premières argileuses a été démontrée pour les constructions en terre de l'époque néolithique (A. DANDRAU, La construction en terre dans le monde égéen préhistorique : les matériaux et leurs propriétés, thèse de doctorat, université de Paris I-Panthéon-Sorbonne [1997], sp. p. 231-279), mais aussi pour certains types de récipients de la même époque : Z. TsirTSONI, P. YIOUNI, « Neolithic Cooking Vessels from Dikili Tash (Eastern Macedonia, Greece) : a Technological and Functional Approach ", in V. KILIKOGLOU, A. Hein, Y. Maniatis (éds), Modern Trends in Scientific Studies on Ancient Ceramics, Papers Presented at the 5th European Meeting on Ancient Ceramics, Athens 1999 (2002), p. 103-110. 


\section{La prospection géologique et l'échantillonnage de sédiments naturels}

Les zones de prospection ont été choisies en fonction de critères archéologiques et technologiques.

Le premier élément pris en compte était l'implantation des sites néolithiques ayant livré des céramiques «noir sur rouge ». En effet, lorsqu’on cherche à restituer les milieux de fabrication des poteries, on doit raisonner en fonction de l'énergie demandée pour le prélèvement des quantités de matières premières nécessaires à la fabrication des vases et pour leur transport depuis les lieux d'extraction jusqu'aux lieux de fabrication ${ }^{61}$. Cela se traduit habituellement en distances entre l'habitat et les sources de matières premières ou en temps nécessaire pour couvrir ces distances, avec la force de l'homme comme principal moyen de transport ${ }^{62}$. Les paramètres de la distance et des moyens de transport dépendent bien évidemment de l'échelle de production et donc de la quantité de matériaux indispensables ${ }^{63}$, tandis que le rôle du relief est aussi un paramètre qui doit être pris en compte ${ }^{64}$. Il est néanmoins généralement admis qu'en contexte non industriel la distance que couvrent les potiers pour se procurer des matières premières est, le plus souvent, de l'ordre de $1 \mathrm{~km}$ pour les argiles et de $3 \mathrm{~km}$ pour les dégraissants, tandis qu'elle ne dépasse en aucun cas les $7 \mathrm{~km}$ du lieu de fabrication ${ }^{65}$. Ce que l'on sait de la production des poteries néolithiques en Grèce du Nord paraît conforme à ces estimations : en effet, la production semble s'appuyer sur l'exploitation de sources d'argile proches des habitats,

61. C. Sinopoli, Approaches to Archaeological Ceramics (1991), p. 15-16.

62. Les empreintes laissées par un filet de portage sur une motte de terre brûlée retrouvée à Dikili Tash constituent une bonne indication des méthodes de portage adoptées par les populations néolithiques. Cet ustensile aurait pu être porté soit sur des épaules humaines soit sur le dos d'animaux domestiques pouvant être bâtés : S. MARTINEZ, "Un filet de portage du Néolithique Récent à Dikili Tash (Macédoine orientale, Grèce) ", in P. Bodu, Cl. Constantin (dir.), Approches fonctionnelles en Préhistoire. Actes du XXVe congrès préhistorique de France, Nanterre, 24-26 novembre 2000 (2004), p. 217-222.

63. S. VAN DER LeEUW, "Towards a Study of the Economics of Pottery Making ", in B. L. V. BeEK, R. W. BRANDT, W. GroenMan-VAN WAATERINGE (éds), Ex horreo (1977), p. 70-71.

64. J. Guilaine, J.-C. Revel, « Pédologie et archéologie », in J. Guilaine (éd.), Pour une archéologie agraire (1991), p. 323-343.

65. W. Deboer, D. Lathrap, "The Making and Breaking of Shipibo-Konibo Ceramics ", in C. Kramer (éd.), Ethnoarchaeology: Implications of Ethnography for Archaeology (1979), p. 102-138, sp. p. 110 ; P. M. RiCE, Pottery Analysis. A Sourcebook (1987), p. 116, 177 ; D. E. ARnold, Ceramic Theory and Cultural Process (1985), p. 38-52 ; id., "Does the Standardisation of Ceramic Pastes Really Mean Specialisation? ", Journal of Archaeological Method and Theory 7, 4 (2000), p. 343 ; D. E. ARNOLD, H. NeFF, R. L. Bishop, "Compositional Analysis and the "Sources" of Pottery : an Ethnoarchaeological Approach ", AmerAnthropologist 93 (1991), p. 70-90, sp. p. 85-86. 
comme le suggèrent les recherches menées à Vassilika ${ }^{66}$, Promachon-Topolnitsa ${ }^{67}$, Néa Nikomédia ${ }^{68}$ et Mégalo Nissi Galanis ${ }^{69}$.

Ainsi, la prospection et l'échantillonnage ont été exhaustifs, d'abord aux environs des principaux sites qui ont fourni du matériel abondant et stratifié, représentatif de la gamme typologique de la céramique étudiée : Sitagri, Dikili Tash, Dimitra et Kryonéri. On a parcouru ensuite les plaines de Drama et de Serrès, ainsi que la partie occidentale de la vallée de la Piérie, où l'on constate une forte présence de céramiques «noir sur rouge » dans le matériel connu par des sondages ou par des prospections. L'on s'est concentré sur les alentours des sites qui ont livré un matériel abondant et/ou significatif sur le plan typologique, tout en essayant de couvrir géographiquement la région étudiée : les sites d'Akropotamos et de Galepsos se trouvent au centre de la zone côtière, Toumba et Tholos sont au centre de la basse vallée du Strymon, tandis que Zervochori et Paradisos sont situés respectivement aux extrémités occidentale et orientale de la région étudiée. La prospection s'est concentrée sur un rayon de 2 à $3 \mathrm{~km}$ autour de ces sites.

Le deuxième critère était celui de l'adaptabilité des terres argileuses présentes dans ce rayon pour le façonnage de poteries du type «noir sur rouge ». Tous les sites sont installés soit sur les parties médianes et distales des grands épandages pléistocènes soit sur les plateaux néogènes, à proximité des sources et le long des cours d'eau pérennes ${ }^{70}$. De fait, il existe une gamme relativement large de terres argileuses dans leur environnement immédiat. Les populations néolithiques avaient sans doute une bonne connaissance des propriétés de ces terres par leurs travaux agricoles, ainsi que par l'exploitation de ressources argileuses en vue de différentes activités artisanales (construction, manufacture d'outils, de figurines). Les recherches sur la nature des sols utilisés pour l'agriculture suggèrent que l'on privilégiait les sols calcimagnésiques brunifiés sur les formations

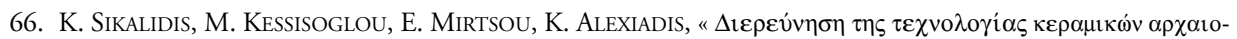

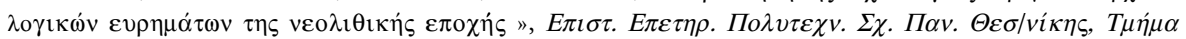

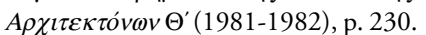

67. P. Yiouni et al., loc. cit. (supra, n. 30).

68. G. PYKE, P. Yiouni, Nea Nikomedeia : The Excavation of an Early Neolithic Village in Northern Greece, 1961-1964, I. The Excavation and the Ceramic Assemblage, ABSA Suppl. 25 (1996), p. 76.

69. A. Kalogirou, Production and Consumption of Pottery in Kitrini Limni, West Macedonia, Greece, 4500 B.C.3500 B.C., Ph. D., Indiana University (1994), p. 217.

70. M. FOTIADIS, Economy, Ecology and Settlement among Subsistence Farmers in the Serres Bassin, Northeastern Greece, 5000-1000 B.C., Ph. D., University of California (1985) ; D. BloueT, « Development of the Settlement Pattern ", in C. Renfrew, M. Gimbutas, E. Elster (éds), Excavations at Sitagroi : A Prehistoric Village in Northeast Greece I (1986), p. 133-143; L. LESPEZ, op. cit. (supra, n. 51). 
néogènes ${ }^{71}$ et, en second lieu, les sols bruns rubéfiés, souvent argileux, développés sur les sections intermédiaires des épandages pléistocènes ${ }^{72}$. Naturellement, les potiers préhistoriques avaient une perception des matériaux différente de celle des chercheurs modernes et procédaient à la sélection des terres en s’appuyant essentiellement sur leur expérience pratique $^{73}$. Ils devaient donc utiliser des critères tels que la couleur, la texture ou le comportement de la terre aux différents stades de la chaîne opératoire. Pour notre prospection, nous avons essayé de procéder, dans toute la mesure du possible, en suivant les mêmes critères qu'eux, en associant à nos connaissances scientifiques sur la composition minéralogique des sédiments la perception visuelle et tactile directe de ces derniers.

Nous avons donc privilégié l'échantillonnage dans des sédiments argileux fins, décarbonatés et rubéfiés, situés à proximité des sites étudiés. Cependant, afin de disposer du maximum d'information possible sur les argiles de la région, nous avons prélevé ponctuellement des argiles carbonatées, en particulier au sein des sédiments palustres néogènes et quaternaires (tableau 10).

Les sédiments argileux décarbonatés et riches en oxydes de fer se retrouvent principalement, en Macédoine orientale, dans les formations de piémont plio-pléistocènes. En effet, le démantèlement par l'érosion des massifs montagneux du Rhodope a entraîné la mise en place de formations détritiques grossières, alternant avec des horizons fins rouges plus ou moins argileux. L'épaisseur de ces derniers est le plus souvent d'ordre métrique et atteint exceptionnellement une puissance plus importante (supérieure à $10 \mathrm{~m}$ ), comme aux environs du site de Paradisos. Cette disposition explique le morcellement des ressources argileuses qui a nécessité un échantillonnage important. Une cinquantaine d'affleurements ont été repérés et échantillonnés. Pour chaque affleurement, nous avons prélevé $1 \mathrm{~kg}$ de sédiment, que l'on a utilisé pour des essais de façonnage et de cuisson, ainsi que pour l'analyse chimique.

Cette procédure d'échantillonnage excluait, néanmoins, les sédiments argileux susceptibles d'être disponibles à la fin du Néolithique Récent dans les fonds de vallée (basse vallée du Strymon et de l'Angitis, marais de Philippes), car ces espaces sont aujourd'hui partout recouverts de plusieurs mètres de dépôts plus récents et leur échantillonnage aurait nécessité l'emploi de techniques plus lourdes (carottages).

71. J. BinTLIFF, Natural Environment and Human Settlement in Prehistoric Greece (1977), p. 106.

72. Les sols alluviaux évolués sur les sédiments limono-sableux dans le fond des vallées apparaissent secondaires, mais il est possible qu'ils aient joué un rôle important dans les activités agricoles des populations néolithiques : T. H. Van Andel, K. Gallis, G. ToufEXIS, «Early Neolithic Farming in a Thessalian River Landscape, Greece», in J. LEWIN, M. G. MACKLIN, J. C. WOODWARD (éds), Mediterranean Quaternary River Environments (1995), p. 131-143; L. LESPEZ, op. cit. (supra, n. 51 [1999]), p. 167.

73. K. NiCKLin, "The Location of Pottery Manufacture", Man 14 (1979), p. 436-458 ; P. M. RicE, op. cit. (supra, n. 65), p. 52. 
TABlEAU 10. LISTE ET CARACTÉRISATION MACROSCOPIQUE DES SÉDIMENTS NATURELS ANALYSÉS

\begin{tabular}{|c|c|c|c|c|c|}
\hline $\begin{array}{c}\mathbf{N}^{\circ} \\
\text { d'échant. }\end{array}$ & Site et localisation & $\begin{array}{c}\text { Distance } \\
\text { du site }\end{array}$ & Contexte géomorphologique & Gisement & Caractéristiques du sédiment \\
\hline $9 \mathrm{~K}$ & Site de Kryonéri & $10 \mathrm{~m}$ & Formations pléistocènes de piémont & Coupe & $\begin{array}{l}\text { Argileux brun-rouge, à sables fins (quartz), micas abondants ; assez } \\
\text { facile à travailler }\end{array}$ \\
\hline $10 \mathrm{M}$ & $\begin{array}{c}\text { Colline 133 } \\
\begin{array}{c}\text { À l'entrée de Messolakia, sur la gauche } \\
\text { de la route Amphipoli-Serrès }\end{array} \\
\end{array}$ & $500 \mathrm{~m}$ & Formations pléistocènes de piémont & Coupe & $\begin{array}{l}\text { Argileux brun-rouge à sables fins, graviers, micas, carbonates ; } \\
\text { assez dur, nécessite beaucoup d'eau pour être travaillé }\end{array}$ \\
\hline $12 \mathrm{M}$ & \begin{tabular}{|c|} 
Colline 133 \\
À l'Ouest du cimetière de Messolakia, replat à $13-$ \\
$14 \mathrm{~m}$ d'altitude
\end{tabular} & $1000 \mathrm{~m}$ & Formations pléistocènes de piémont & Sol & $\begin{array}{l}\text { Argileux rouge comportant une fraction grossière modeste (micas et } \\
\text { quartz abondants) ; assez plastique }\end{array}$ \\
\hline $13 \mathrm{M}$ & \begin{tabular}{|c|} 
Colline 133 \\
$\begin{array}{c}\text { À la sortie de Messolakia, sur la droite de la route } \\
\text { Amphipolis-Serrès après le pont }\end{array}$ \\
\end{tabular} & $500 \mathrm{~m}$ & Formations pléistocènes de piémont & Sol & $\begin{array}{l}\text { Argilo-limoneux rouge à sables fins abondants (micas) ; } \\
\text { assez plastique }\end{array}$ \\
\hline $14 M$ & \begin{tabular}{|c|} 
Colline 133 \\
À la sortie de Messolakia \\
(après le pont, 400 m plus loin que 13M) \\
sur la droite de la route Amphipolis-Serrès
\end{tabular} & $900 \mathrm{~m}$ & Formations pléistocènes de piémont & Coupe & $\begin{array}{l}\text { Argilo-limoneux rouge à sables peu abondants (micas), concrétions } \\
\text { calcaires et ferro-manganiques ; } \\
\text { assez difficile à travailler }\end{array}$ \\
\hline 15D & $\begin{array}{c}\text { Dimitra } \\
\text { Au Sud-Est du site } \\
\end{array}$ & $300 \mathrm{~m}$ & Formations marneuses néogènes & Sol & $\begin{array}{l}\text { Argileux gris clair à mica fin et petites concrétions ferro- } \\
\text { manganiques; assez dur et difficile à travailler }\end{array}$ \\
\hline 17D & $\begin{array}{c}\text { Dimitra } \\
\text { À l'entrée de Domiros, à droite de la route }\end{array}$ & $3500 \mathrm{~m}$ & Formations pléistocènes de piémont & Coupe & $\begin{array}{c}\text { Argilo-limoneux ocre à sables fins peu abondants (micas), à nodules } \\
\text { calcaires, concrétions ferro-manganiques abondantes }\end{array}$ \\
\hline 18D & $\begin{array}{c}\text { Dimitra } \\
\text { Entre Domiros et Komatadès, à gauche de la route }\end{array}$ & $5000 \mathrm{~m}$ & Formations pléistocènes de piémont & Sol & $\begin{array}{l}\text { Argileux rouge à sables abondants (quartz, carbonate) ; } \\
\text { très plastique, facile à travailler }\end{array}$ \\
\hline 19D & $\begin{array}{c}\text { Dimitra } \\
\text { À l'entrée de Domiros, à droite de la route }\end{array}$ & $3500 \mathrm{~m}$ & Formations pléistocènes de piémont & $\begin{array}{c}\text { Coupe } \\
\text { (même que 17D } \\
\text { mais prélevé dans } \\
\text { un niveau } \\
\text { supérieur) }\end{array}$ & $\begin{array}{l}\text { Argilo-limoneux rouge, à nodules calcaires et concrétions ferro- } \\
\text { manganiques ; difficile à travailler, nécessite beaucoup d'eau }\end{array}$ \\
\hline 20D & $\begin{array}{c}\text { Dimitra } \\
\text { Entre Domiros et Myrini, à gauche de la route } \\
\end{array}$ & $3000 \mathrm{~m}$ & Formations pléistocènes de piémont & Sol & $\begin{array}{l}\text { Argileux brun foncé à sables calcaires abondants et rares micas ; } \\
\text { assez dur, difficile à travailler }\end{array}$ \\
\hline $21 G$ & $\begin{array}{l}\text { Galepsos } \\
\text { Entre Galepsos et Kokkinochori, près de } \\
\text { Galepsos, à gauche de la route }\end{array}$ & $750 \mathrm{~m}$ & Formations pléistocènes de piémont & Coupe & $\begin{array}{l}\text { Argilo-limoneux rouge à sables et graviers abondants (quartz, } \\
\text { carbonates, micas); assez friable, beaucoup d'inclusions }\end{array}$ \\
\hline 23Th & $\begin{array}{l}\text { Tholos } \\
\text { Dans une carrière le long de la route Drama- } \\
\text { Serrès }\end{array}$ & $2000 \mathrm{~m}$ & Formations pléistocènes de piémont & Coupe & $\begin{array}{l}\text { Argileux rouge à concrétions ferro-manganiques abondantes et } \\
\text { sables fins (micas) ; assez plastique }\end{array}$ \\
\hline $27 \mathrm{~T}$ & $\begin{array}{c}\text { Toumba } \\
\text { Sur la route Serrès-Drama, après le carrefour de } \\
\text { Toumba }\end{array}$ & $2500 \mathrm{~m}$ & Formations pléistocènes de piémont & Coupe & $\begin{array}{l}\text { Argileux rouge, décarbonaté à micas fins abondants, sables } \\
\text { quartzeux rares, concrétions ferro-manganiques peu abondantes ; } \\
\text { très plastique, facile à travailler }\end{array}$ \\
\hline 29G & $\begin{array}{c}\text { Galepsos } \\
\text { Au pied du site à l'Ouest, dans le ravin d'Arapis } \\
\end{array}$ & $250 \mathrm{~m}$ & Formations pléistocènes de piémont & Coupe & $\begin{array}{c}\text { Argileux rouge à micas et sables abondants; } \\
\text { assez facile à travailler quand on enlève les inclusions }\end{array}$ \\
\hline 30A & $\begin{array}{c}\text { Akropotamos } \\
\text { Entre Podochori et Akropotamos, à droite de la } \\
\text { route }\end{array}$ & $2000 \mathrm{~m}$ & Formations pléistocènes de piémont & Sol & $\begin{array}{l}\text { Argileux rouge à sables abondants (quartz, micas, carbonates) et } \\
\text { rares concrétions ferro-manganiques ; très plastique, bon à } \\
\text { travailler, il faut enlever les inclusions }\end{array}$ \\
\hline 31Dkt & $\begin{array}{l}\text { Dikili Tash } \\
\text { Incision près du parking du thêâtre de Philippes }\end{array}$ & $2000 \mathrm{~m}$ & Formations pléistocènes de piémont & Sol & $\begin{array}{l}\text { Argileux rouge à sables quartzeux et micas fins abondants, rares } \\
\text { concrétions ferro-manganiques ; très plastique, beaucoup } \\
\text { d'inclusions à enlever }\end{array}$ \\
\hline 32Dkt & $\begin{array}{c}\text { Dikili Tash } \\
\text { Au pied du Profitis Ilias (village de Philippi) }\end{array}$ & $3000 \mathrm{~m}$ & Formations pléistocènes de piémont & Coupe & $\begin{array}{l}\text { Argilo-limoneux brun-rouge légèrement sableux (micas fins } \\
\text { abondants, quartz, carbonates); moins facile à travailler que 31Dkt }\end{array}$ \\
\hline 33Dkt & $\begin{array}{c}\text { Dikili Tash } \\
\begin{array}{c}\text { À droite de la route Kavala-Krénidès, } \\
\text { à l'entrée du village }\end{array} \\
\end{array}$ & $1000 \mathrm{~m}$ & Formations pléistocènes de piémont & Coupe & Argileux rouge à sables abondants (quartz, micas) ; peu plastique \\
\hline $34 S$ & $\begin{array}{c}\text { Sitagri } \\
\text { Au Sud-Est du tell }\end{array}$ & $500 \mathrm{~m}$ & $\begin{array}{l}\text { Sol vertique sur formations pléistocènes } \\
\text { de piémont }\end{array}$ & Sol & $\begin{array}{l}\text { Argileux noir à sables fins assez abondants (quartz, micas rares) ; } \\
\text { assez dur, difficile à travailler }\end{array}$ \\
\hline
\end{tabular}




\begin{tabular}{|c|c|c|c|c|c|}
\hline $\begin{array}{l}N^{\circ} \\
\text { d'échant. }\end{array}$ & Site et localisation & $\begin{array}{l}\text { Distance } \\
\text { du site }\end{array}$ & Contexte géomorphologique & Gisement & Caractéristiques du sédiment \\
\hline $35 S$ & $\begin{array}{c}\text { Sitagri } \\
\text { À la sortie du village de Sitagri, } \\
\text { sur la route vers Mikrochori, à droite }\end{array}$ & $3500 \mathrm{~m}$ & Formations pléistocènes de piémont & Sol & $\begin{array}{l}\text { Argileux brun à sables (quartz, carbonate, rares micas); } \\
\text { facile à travailler }\end{array}$ \\
\hline $36 \mathrm{~S}$ & $\begin{array}{c}\text { Sitagri } \\
\text { Entre Sitagri et Mikrochori, à gauche de la route } \\
\end{array}$ & $4500 \mathrm{~m}$ & Formations pléistocènes de piémont & Sol & $\begin{array}{l}\text { Argileux brun-rouge à sables fins micacés ; } \\
\text { malléable, grandes inclusions }\end{array}$ \\
\hline $37 \mathrm{~S}$ & $\begin{array}{c}\text { Sitagri } \\
\text { En rive gauche de l'Angitis, deuxième replat en } \\
\text { venant du cours d'eau }\end{array}$ & $2500 \mathrm{~m}$ & Formations pléistocènes de piémont & Coupe & $\begin{array}{l}\text { Argileux ocre-orange à sables et concrétions calcaires ; } \\
\text { très plastique, bon à travailler }\end{array}$ \\
\hline $39 \mathrm{~S}$ & $\begin{array}{c}\text { Sitagri } \\
\text { Sur un replat au pied d'Alistrati } \\
\end{array}$ & $2500 \mathrm{~m}$ & Formations pléistocènes de piémont & Sol & $\begin{array}{l}\text { Argilo-limoneux rouge à sables quartzeux et carbonatés assez } \\
\text { abondants ; difficile à travailler }\end{array}$ \\
\hline $40 S$ & $\begin{array}{c}\text { Sitagri } \\
\text { À côté d'un entrepôt de coton sur la route } \\
\text { d'Alistrati }\end{array}$ & $2500 \mathrm{~m}$ & Formations pléistocènes de piémont & Sol & $\begin{array}{l}\text { Limono-argileux rouge à sables quartzeux et micacés ; } \\
\text { difficile à travailler }\end{array}$ \\
\hline 41A & \begin{tabular}{c|c} 
Akropotamos & \\
Au Nord-Est du site & \\
\end{tabular} & $500 \mathrm{~m}$ & Formations marno-calcaires néogènes & Coupe & $\begin{array}{c}\text { Argilo-sableux brun-rouge (quartz et carbonates) } \\
\text { très plastique, mais il faut enlever les inclusions }\end{array}$ \\
\hline $42 \mathrm{~A}$ & \begin{tabular}{|c|} 
Akropotamos \\
Au pied du site, à gauche de la route vers Karyani
\end{tabular} & $200 \mathrm{~m}$ & Formations pléistocènes de piémont & Coupe & $\begin{array}{l}\text { Limono-argileux café au lait à sables quartzeux et carbonatés } \\
\text { abondants ; très plastique }\end{array}$ \\
\hline $45 Z$ & \begin{tabular}{|c|} 
Zervochori \\
Au pied de la butte qui porte le site \\
\end{tabular} & $200 \mathrm{~m}$ & Formations pléistocènes de piémont & Coupe & Argilo-limoneux rouge à sables fins abondants et graviers \\
\hline 47P & $\begin{array}{c}\text { Paradisos } \\
\text { Au pied des versants montagneux, à } 1 \mathrm{~km} \text { à } \\
\text { l'Est/Nord-Est du site }\end{array}$ & $1000 \mathrm{~m}$ & Formations pléistocènes de piémont & Coupe & $\begin{array}{l}\text { Argileux presque pur, très rouge à nodules ferrugineux ; } \\
\text { très plastique, bon à travailler }\end{array}$ \\
\hline 48Dkt & $\begin{array}{c}\text { Dikili Tash } \\
\begin{array}{c}\text { Dans un champ, au Sud du site, près du } \\
\text { croisement de la route vers Philippi }\end{array} \\
\end{array}$ & $500 \mathrm{~m}$ & Formations palustres holocènes & Sol & $\begin{array}{l}\text { Limono-argileux noir à micas fins assez abondants, à sables fins } \\
\text { rares et peu abondants ; assez facile à travailler }\end{array}$ \\
\hline 49Dkt & $\begin{array}{c}\text { Dikili Tash } \\
\text { Dans un champ à l'Est du tell, près du drain } \\
\end{array}$ & $50 \mathrm{~m}$ & Formations pléistocènes de piémont & Sol & Argileux gris-brun à sables abondants (micas) \\
\hline 50Dkt & 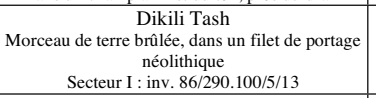 & $0 \mathrm{~m}$ & - & - & Argileux à sables quartzeux et concrétions carbonatées abondants \\
\hline 51Amf & $\begin{array}{c}\text { Amphipolis } \\
\text { Dans le village, coupe dans le terrain de l'église } \\
\text { du village }\end{array}$ & & Formations marneuses néogènes & Sol & Argileux gris à micas et sables fins rares \\
\hline 52Amf & $\begin{array}{c}\text { Amphipolis } \\
\text { Coupe sur le chemin vers Kerdyllia, derrière le } \\
\text { Lion }\end{array}$ & & Formations marneuses néogènes & Coupe & Argileux gris à micas et sables fins rares \\
\hline 53Amf & $\begin{array}{c}\text { Colline } 133 \\
\text { dans un champ cultivé au N-E de la colline } \\
\end{array}$ & & Formations marneuses néogènes & Sol & Argileux gris à micas fins rares et cailloux quartzeux peu abondants \\
\hline 54Kok & $\begin{array}{c}\text { Kokkinochori } \\
\text { dans un champ cultivé à l'entrée orientale du } \\
\text { village, au Sud de la route régionale }\end{array}$ & & Formations pléistocènes de piémont & Sol & $\begin{array}{l}\text { Argileux rouge à sables quartzeux faiblement micacé ; } \\
\text { très plastique }\end{array}$ \\
\hline
\end{tabular}




\section{Caractérisation des sédiments naturels et comparaison avec les pâtes céramiques}

\section{Les observations macroscopiques}

Des observations macroscopiques précises ont porté sur les 34 échantillons sélectionnés pour analyse (parmi les 53 prélevés au total) après les premiers essais de façonnage, ainsi que sur l'unique échantillon archéologique (cf. infra).

26 échantillons avaient été prélevés en coupe dans des horizons fins rubéfiés, au sein des formations plio-pléistocènes ou à leur surface, dans les sols actuels. Ces sédiments étaient toujours plastiques, plus ou moins sableux, de couleur rouge ou brun-rouge. Seuls 9 échantillons étaient naturellement peu sableux (9K, 14M, 17D, 19D, 23Th, 27T, 36S, $47 \mathrm{P})$, tandis que les autres présentaient une granulométrie généralement plus grossière que celle des pâtes céramiques. Les sables sont quartzo-feldspathiques (12M, 18D, 21G, 29G, 30A, 31Dkt, 32Dkt, 33Dkt, 35S, 39S, 40S, 41A, 45Z, 54Kok) ou/et micacés (9K, 10M, 12M, 13M, 21G, 23Th, 27T, 29G, 30A, 31Dkt, 32Dkt, 40S, 45Z). Les sédiments ayant connu une évolution pédologique comportent également des concrétions calcaires (10M, 14M, 17D, 19D, 20D, 37S) et certains échantillons contiennent des concrétions ferro-manganiques (14M, 17D, 19D, 23Th, 27T, 30A, 31Dkt, 47P).

Huit échantillons correspondent à des formations argileuses de couleur grise à noire. Il s'agit de sédiments issus des bordures d'anciens espaces marécageux (48Dkt, 49Dkt), de sédiments vertiques $(34 \mathrm{~S})$, de sols développés sur les formations néogènes (15D) ou de sédiments prélevés dans ces mêmes formations (42A, 51AMF, 52AMF, 53AMF). Les échantillons $48 \mathrm{Dkt}$, 49Dkt et $34 \mathrm{~S}$ correspondent à des sédiments distaux comportant une fraction sableuse fine micacée. Les sédiments 51AMF, 52AMF, 53AMF sont fins, gris et comportent une faible fraction sableuse micacée. Par ailleurs, ils sont dépourvus de concrétions calcaires même si leur origine et leur couleur suggèrent une teneur en carbonates importante. L'échantillon $42 \mathrm{~A}$ présente une fraction sableuse quartzo-feldspathique et calcaire.

Enfin, l'échantillon 50Dkt provient d'une motte de terre brûlée trouvée dans des couches du Néolithique Récent I (un peu avant 5000 av. J.-C.) à Dikili Tash. Portant des empreintes laissées par un filet de portage, cette motte de sédiment argilo-sableux représente probablement de la matière première de l'époque ${ }^{74}$.

74. Supra, n. 62. 


\section{Les essais de cuisson}

Les 53 échantillons prélevés durant la prospection ont fait l'objet d'un premier essai de façonnage, afin de tester leur aptitude (malléabilité, plasticité) pour la fabrication des poteries. 19 échantillons ont été écartés à la suite de ces essais.

Ensuite, les 34 échantillons conservés ont servi à la fabrication de briquettes expérimentales. Deux séries de briquettes mesurant $1 \times 1,5 \times 3 \mathrm{~cm}$ ont été préparées, l'une à partir de sédiments qui n’avaient subi aucun traitement et l'autre à partir des mêmes sédiments tamisés à $1 \mathrm{~mm}$. La plasticité des sédiments s'est améliorée considérablement après le tamisage et l'enlèvement des éléments non plastiques volumineux. En effet, la plupart des échantillons tamisés étaient faciles à travailler et tenaient bien au malaxage et au façonnage. Le séchage n’a provoqué des fissures que sur un échantillon (34S) : cela s'explique par la forte teneur de ce sédiment, issu d'un sol vertique, en argile gonflante (smectite). Les briquettes ont enfin été cuites pour tester le comportement des sédiments à la cuisson.

La cuisson a été effectuée dans un four électrique (Nabertherm C6) au laboratoire du musée de Philippes. Une première cuisson a été effectuée à la température de $850^{\circ} \mathrm{C}$ et une deuxième à la température de $950^{\circ} \mathrm{C}$, à chaque fois pendant une heure. La température finale a été atteinte en quatre et deux heures respectivement. Des informations concernant la texture et la couleur des échantillons ont été enregistrées à différents moments de la procédure : avant la cuisson, à l'état humide et à l'état sec, ainsi qu'après chaque cuisson.

Après cuisson toutes les briquettes ont perdu presque $10 \%$ de leur volume. Les briquettes de l'échantillon $39 \mathrm{~S}$ ont éclaté à cause de l'abondance des concrétions calcaires dans la pâte. L'échantillon non tamisé $37 \mathrm{~S}$ a également éclaté à $950^{\circ} \mathrm{C}$, alors qu'il était resté intact à la température de $850^{\circ} \mathrm{C}$; le même sédiment tamisé n’a pas éclaté. La cuisson a provoqué de petites fissures sur les échantillons non tamisés $40 \mathrm{~S}$ et 20D. L'échantillon $45 \mathrm{Z}$ est devenu friable, probablement à cause de l'abondance des micas inclus dans la pâte. Les échantillons non tamisés $30 \mathrm{~A}$ et $42 \mathrm{~A}$ sont aussi devenus friables. Par ailleurs, les fissures provoquées par le séchage de l'échantillon $34 \mathrm{~S}$ n'ont pas été aggravées par la cuisson. Tous les autres échantillons ont bien résisté à la haute température et présentaient, après cuisson, un aspect compact et dur.

Les couleurs obtenues sont très proches de celles des céramiques étudiées. Presque tous les échantillons ont cuit rouge (2.5YR 5/6 à 2.5 YR 5/8, d'après le code Munsell), y compris ceux provenant de sédiments de couleur brune ou noire. Les couleurs obtenues après la cuisson à la température de $850^{\circ} \mathrm{C}$ sont devenues beaucoup plus vives après la cuisson à $950^{\circ} \mathrm{C}$. Seul l'échantillon $15 \mathrm{D}$, de couleur initiale gris clair-beige, a pris une couleur blanc-beige; cela s'explique par sa forte teneur en carbonate de calcium. 
Trois échantillons ont donc été jugés impropres en tant que terres à poteries «noir sur rouge " : les $39 \mathrm{~S}$ et $45 \mathrm{Z}$, à cause de leur fragilité mécanique après cuisson, et le $15 \mathrm{D}$, à cause de sa couleur blanche. Tous les autres échantillons conviennent dans la mesure où, une fois tamisés, ils ont donné des résultats satisfaisants.

\section{La composition chimique des sédiments}

L'analyse chimique par activation neutronique (NAA) a porté sur 35 échantillons au total (34 échantillons de sédiments naturels, plus celui prélevé sur la motte de terre néolithique de Dikili Tash). Il s'agissait de comparer leurs compositions avec les moyennes des quatre grands types de pâtes céramiques identifiés (supra, p. 22-26). Bien que les résultats des analyses chimiques ne permettent pas d'établir une identité de composition entre matériel archéologique et prélèvements naturels, ils permettent de formuler une série d'observations sur la localisation des sources des terres à poteries «noir sur rouge » en Macédoine orientale (tableau 11).

D’une manière générale, les teneurs obtenues pour l'uranium (U) et le rubidium (Rb) sont presque toujours nettement inférieures dans les échantillons géologiques à celles obtenues dans les pâtes céramiques, alors même que les sols et les sédiments en Macédoine orientale sont connus pour posséder des valeurs plus élevées que dans le reste de la Grèce. Cela pourrait s'expliquer par des phénomènes de mobilité géochimique des éléments radioactifs.

Par ailleurs, les argiles échantillonnées ne forment pas des groupes de composition homogènes. Plus précisément, les argiles sont assez différentes entre elles au niveau de leur composition chimique et ne se regroupent pas clairement. Même les terres prélevées dans la même région et dans un même contexte géologique présentent parfois des divergences relativement importantes. Ce sont seulement les échantillons des environs de Kryonéri et de la Colline 133 (échantillons 10M, 12M, 13M, 14M) qui entrent dans un groupe de composition assez cohérent, tandis que trois des échantillons des environs de Sitagri (34S, 36S, 40S) en forment un autre. Deux échantillons de Dikili Tash (31Dkt et 33Dkt) se groupent également, de même que deux échantillons des environs de Galepsos (29G et $21 \mathrm{G})$. Tous les autres échantillons présentent une assez forte dispersion.

La teneur très marquée en calcium $(\mathrm{Ca})$ de certains échantillons est à souligner (17D, 20D, 35S, 37S, 48Dkt, 49Dkt, 30A, et surtout 15D) : elle indique la présence très forte de concrétions calcaires, chose que l'on avait déjà notée lors de l'observation macroscopique (supra). Par ailleurs, l'échantillon 15D présente la teneur la plus importante en Ca, ce qui explique la couleur blanche de cette argile. La teneur importante en fer (Fe) des échantillons 47P, 27T et 45Z, reconnus comme de la « terra rossa ", était attendue.

TABleau 11. Composition CHIMIQUe DES SÉdimentS NATURELS ANALYSÉS 


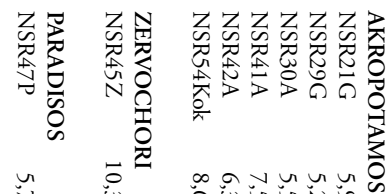

$\dddot{u} \quad \stackrel{\vec{c}}{\sim}$

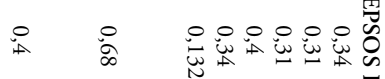

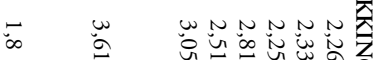

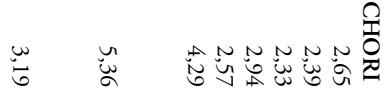

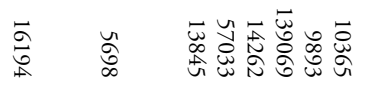

竞 $\quad \stackrel{\infty}{y} \quad \begin{aligned} & \infty \\ & \forall\end{aligned}$

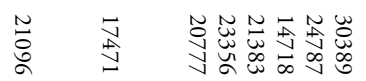

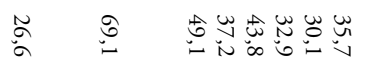

స్ర

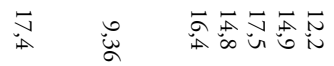

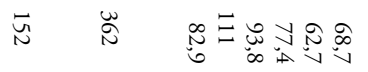

吕

i

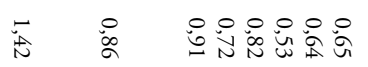

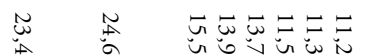

$\exists$

$\breve{n}^{\circ}$

$\stackrel{8}{8}$

$\vdots$

$\stackrel{ }{\mathfrak{N}}$

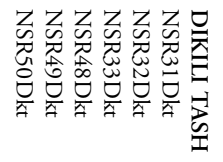

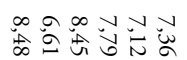

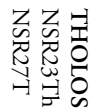

$?$

ํำ

का

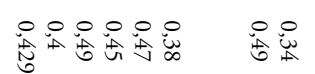

W.

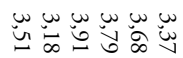

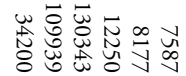

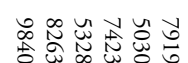

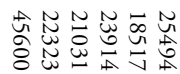

央岕出出出

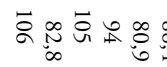

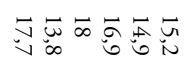



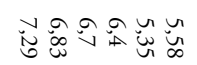

ût

엉엉ㅇㅇㅇㅇㅇ

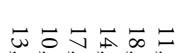

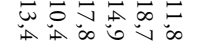

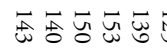

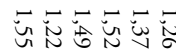

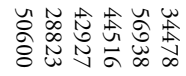

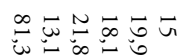

w

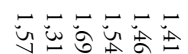

$\underset{N}{\mathbb{N}} \stackrel{\substack{\infty \\ \infty}}{\infty}$

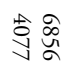

Nָ心

央芯

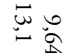

5 :

$\stackrel{\sim}{\sim} \infty$

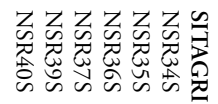

$\circ \circ \circ \infty \circ \overline{0}$

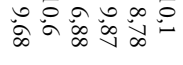

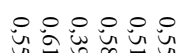

vis

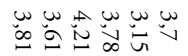

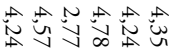

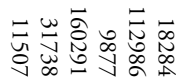

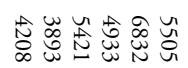

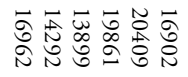

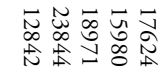

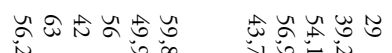

怘岕芯茣志

怘岕茫串

N

ज స

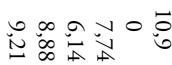

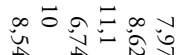

员只品

$\neg \varpi \varpi \varpi \vec{\infty}$

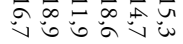

居㤁宫志志志

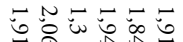

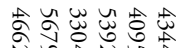

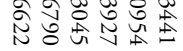

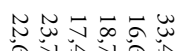

$\leftarrow \sim$

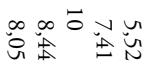

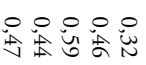

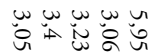

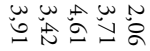

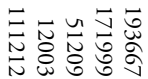

$\vec{\sigma}$

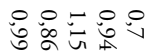

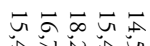

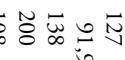

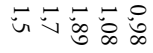

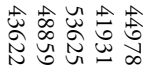

$\overrightarrow{0} \overrightarrow{0} \underset{\sim}{\sim} \underset{\infty}{\infty}$

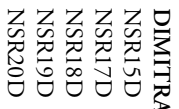

A $\begin{gathered}0 \\ 0\end{gathered}$

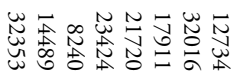

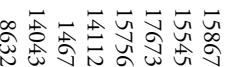

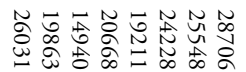

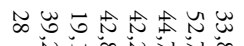

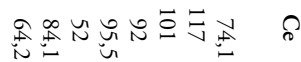

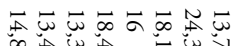

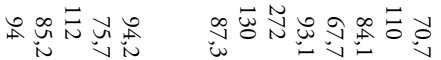

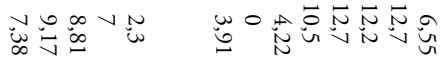

$\pm$

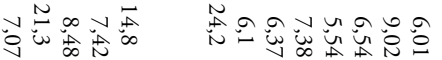

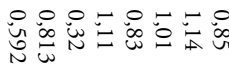

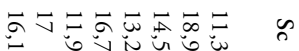

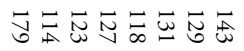

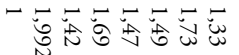

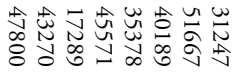

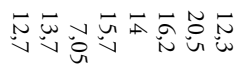

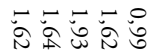

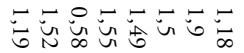


D'autre part, en comparant céramiques et échantillons de terres, nous constatons que la composition chimique des argiles naturelles échantillonnées est, globalement, très différente de celle des céramiques "noir sur rouge " analysées. Elles présentent des différences assez importantes dans la teneur en presque tous les éléments (cf. tableau 2).

Concernant le type de pâte A, la comparaison a été prioritairement réalisée avec les échantillons géologiques prélevés dans l'espace de production identifié (fig. 10 : basse vallée du Strymon et vallée de l'Angitis). Cela concerne 8 échantillons dans le secteur de Kryonéri et de la Colline 133, 4 échantillons prélevés autour de Dimitra, 6 échantillons autour du site de Sitagri et 2 échantillons dans le secteur de Tholos et de Toumba. Les analyses chimiques confirment que la plupart des échantillons prélevés sont, effectivement, peu carbonatés et assez riches en fer, avec des valeurs proches des céramiques étudiées. Par ailleurs, tous les échantillons présentent une grande variabilité de leur composition chimique pour les autres éléments majeurs $(\mathrm{Na}, \mathrm{K})$, ainsi que pour la plupart des éléments traces (écarts-types $>20 \%$ ).

Malgré cette variabilité, aucun des 20 échantillons prélevés ne correspond de manière satisfaisante à la composition des échantillons céramiques. Par exemple, les échantillons $10 \mathrm{M}$ et $14 \mathrm{M}$, prélevés aux environs de la Colline 133 et non loin de Kryonéri, sont sans doute les plus proches par leur composition chimique des échantillons céramiques du type A. Mais leurs teneurs en éléments traces restent encore trop éloignées de celles des échantillons céramiques pour qu'ils puissent être interprétés comme une source de matière première pour la céramique «noir sur rouge ». Aucun des autres échantillons prélevés dans le reste de la Macédoine orientale ne peut convenir non plus. Par exemple, l'échantillon des environs de Paradisos (47P) est assez différent des céramiques analysées du site, dont la plupart se classent dans les groupes de composition 3 et 6 . La terre est caractérisée par une concentration en $\mathrm{Ce}, \mathrm{Cr}$, Hf, Sc et Fe sensiblement plus forte et par une teneur en $\mathrm{Ca}, \mathrm{Na}, \mathrm{K}, \mathrm{Sm}$ et $\mathrm{U}$ moins élevée.

Concernant le type de pâte B, on ne dispose que de 6 échantillons pour la comparaison, qui proviennent tous de la zone proche du littoral à l'Est de l'embouchure du Strymon. Les échantillons prélevés apparaissent en général nettement moins carbonatés que la pâte de la céramique et moins riches en fer. Certains éléments traces présentent également des teneurs trop faibles ( $\mathrm{Th}, \mathrm{Cr}, \mathrm{Cs}, \mathrm{Sc}, \mathrm{Ta}$ ), y compris pour l'échantillon 41A qui présente les teneurs les plus proches de la composition recherchée.

Le seul échantillon naturel analysé dans l'espace de production du type de pâte C (45Z) a été jugé impropre à la fabrication des céramiques (supra, p. 35-36). Néanmoins, sa teneur particulièrement élevée en chrome $(\mathrm{Cr})$ reflète vraisemblablement la composition géochimique des sédiments du massif serbo-macédonien (roches ultrabasiques) et pourrait correspondre à une production également localisée.

Les échantillons prélevés autour de Dikili Tash présentent des différences importantes 
avec les pâtes céramiques de type D. Les échantillons 48Dkt et 49Dkt provenant du marais ou de ses abords ont des teneurs trop élevées en carbonates et trop faibles en fer et ne peuvent convenir. Les 3 échantillons restants (31Dkt, 32Dkt, 33Dkt), prélevés dans un contexte géomorphologique analogue (formations de piémont), présentent des compositions très variées, mais ne correspondent pas à la composition des pâtes céramiques. L'écart est particulièrement important pour le scandium $(\mathrm{Sc})$, dont la teneur est de 2 à 4 fois plus élevée dans les échantillons céramiques que dans les sédiments naturels. L'échantillon archéologique 50Dkt, quoique plus proche, ne correspond pas non plus à la composition des échantillons céramiques de Dikili Tash.

Enfin, l'échantillon 15D, sédiment argileux gris clair qui a cuit blanc, présente, si on le compare avec les céramiques «brun sur crème » analysées (groupe de composition 10), une plus forte concentration en Ca et une teneur plus faible en la plupart des éléments.

\section{La provenance des matériaux argileux}

Cette recherche des matières premières utilisées pour la fabrication des céramiques « noir sur rouge » de Macédoine orientale (faciès 1) conduit aux conclusions suivantes :

1) d'après les analyses, les formations plio-pléistocènes et néogènes sont le milieu contenant les matières recherchées. En revanche, les sédiments marécageux doivent être exclus, car ils présentent des concentrations trop élevées en carbonates, à cause de la présence d'inclusions carbonatées de granulométrie très fine qui ne peuvent pas être enlevées de la pâte ;

2) malgré un prélèvement dans des contextes géomorphologiques proches les uns des autres, les échantillons naturels analysés présentent des compositions très variées. Cela est à mettre en relation avec la diversité des affleurements géologiques qui ont nourri les formations des piémonts. Il apparaît ainsi nécessaire de prendre en compte, pour les éventuelles futures recherches, les caractéristiques géologiques de chaque bassin versant ;

3) la meilleure relation entre les échantillons naturels et le type de pâte céramique est obtenue pour la basse vallée du Strymon (zone de type céramique A). Le rapport est moins bien établi pour la zone littorale (B), alors qu'il pose plus de problèmes pour le type $\mathrm{D}$ de Dikili Tash ;

4) pour l'espace de production de la basse vallée du Strymon et de la vallée de l'Angitis (type A), la variabilité de composition des échantillons naturels souligne encore plus l'homogénéité du type de pâte céramique identifié. Cela permet d'émettre l'hypothèse que toutes les céramiques de ce type ont été élaborées à partir de matières premières provenant d'un seul lieu d'approvisionnement, autrement dit d'une seule et même carrière. Celle-ci n'a pas encore été identifiée, mais elle doit être recherchée dans des formations du même type que celles déjà échantillonnées ; 
5) la même hypothèse pourrait être émise pour les céramiques du type B. Toutefois, le nombre plus faible d'échantillons archéologiques et géologiques nous oblige à être plus prudents. La teneur en carbonates, assez élevée, de ces céramiques nous oriente vers une recherche dans des formations naturelles plus riches en calcaires, comme par exemple les dépôts palustres littoraux;

6) aucun des échantillons naturels de Dikili Tash ne présente une teneur en scandium (Sc) aussi élevée que les échantillons archéologiques. Cela indique l'utilisation d'une ressource particulière, qui reste à identifier.

\section{CONCLUSIONS : PRODUCTION ET CIRCULATION}

L'étude combinée des analyses des échantillons céramiques et des prélèvements naturels nous conduit à supposer que les lieux d'approvisionnement des terres à poteries « noir sur rouge » se situaient soit dans des zones plus éloignées des habitats néolithiques (plus de 2 à $3 \mathrm{~km}$, supra, p. 00), soit en profondeur, dans des gisements recouverts par des alluvions récentes.

En effet, la grande homogénéité de composition chimique de chaque type de pâte suggère l'existence d'un nombre limité de lieux d'approvisionnement pour chaque zone de production. De fait, ceux-ci devaient se trouver loin de certains habitats. Les potiers néolithiques devaient donc aller plus loin pour se procurer des matériaux satisfaisants, ce qui ne paraît guère étonnant, vu les qualités particulières de cette catégorie céramique.

D'autre part, si l'on exclut la possibilité d'un épuisement des gisements exploités au Néolithique, il est possible que ceux-ci soient aujourd'hui masqués suite à des changements géomorphologiques. L'analyse pétrographique indique, en effet, que les terres à poteries " noir sur rouge " proviennent des parties distales des formations alluviales, car elles se caractérisent par une granulométrie très fine. Il faudrait faire un échantillonnage par carottage pour pouvoir trouver des gisements analogues en profondeur.

Par ailleurs, il ne faut pas oublier les paramètres qui peuvent modifier le profil chimique des sédiments naturels pendant la préparation des pâtes. La purification et la cuisson, notamment, constituent des facteurs qui influencent les concentrations en plusieurs éléments ${ }^{75}$. Cela dit, dans notre cas, le paramètre de la cuisson a été pris en compte, puisque les sédiments ont été analysés après avoir été cuits à des températures analogues à celles des céramiques. Le tamisage seul n’aurait pas suffi pour changer radicalement les

75. V. Kilikoglou, Y. Maniatis, A. P. Grimanis, «The Effect of Purification and Firing of Clays on Trace Element Provenance Studies ", Archaeometry 30 (1988), p. 37-46. 
concentrations des éléments. Il est donc possible que les potiers aient employé des méthodes plus sophistiquées de transformation de la matière première, comme la décantation et la lévigation, la maturation des argiles, l'ajout de substances, ou le mélange de plusieurs argiles pour obtenir le matériau voulu.

La combinaison des données archéologiques et archéométriques légitime l'hypothèse d'une fabrication de ces poteries dans plusieurs habitats et conduit à exclure celle d'un centre de production unique. Les potiers des différents habitats suivaient visiblement des normes communes, ce qui indique une communication et une transmission des savoirfaire. D'autre part, la variabilité des caractéristiques technologiques et morphologiques des récipients, même faible, témoigne de l'existence de micro-traditions céramiques distinctes, reflétant une certaine liberté liée à la personnalité des potiers et/ou à des préférences locales ${ }^{76}$.

Certains récipients provenant de la zone de production de la basse vallée du Strymon et de la vallée de l'Angitis (type de pâte A) ont pu arriver à Dikili Tash (cf. supra, tableau 7), alors qu'aucun exemple appartenant au groupe de composition chimique propre à ce site (type D) n'a été trouvé, inversement, dans cette zone (supra, tableau 3). Certes, il ne faut pas confondre céramiques attestées à Dikili Tash et céramiques produites à Dikili Tash, puisqu'on n'a localisé dans les environs du site aucune source pouvant correspondre, de près ou de loin, aux pâtes céramiques du type $\mathrm{D}$ et qu'il est donc possible que les échantillons de ce type soient, eux aussi, importés. Mais, dans tous les cas, il faut admettre qu'il a pu y avoir des zones avec une production plus dynamique que d'autres et dont les produits se diffusaient à l'extérieur, à des distances plus ou moins importantes. La proximité géographique pouvait influencer l'échelle de diffusion, comme le montre en particulier le chevauchement dans la répartition des céramiques dans les sites de la basse vallée du Strymon et ceux du littoral (fig. 10). L'exemple de Galepsos est caractéristique de cette osmose, puisque les échantillons analysés témoignent d'une appartenance aux deux zones de production, dans des proportions presque égales.

Au total, on soulignera l'abondance et la subtilité des facteurs intervenant dans l'organisation des chaînes de production et de diffusion des céramiques à une époque aussi reculée que le Néolithique et les précautions à prendre lors de leur interprétation. Cette étude marque une étape vers une meilleure compréhension de ces phénomènes. Ses résultats invitent à poursuivre la recherche des matières premières ayant servi à la fabrication des poteries du faciès 1 dans les directions pressenties et à entreprendre des travaux du même ordre pour les autres faciès.

76. Voir sur ce sujet : Z. Tsirtsoni, D. Malamidou, V. Kilikoglou, I. Karatasios, L. LespeZ, « Black-on-red Painted Pottery. Production and Distribution in Late Neolithic Macedonia ", in S. WAKsman (éd.), Archaeometric and Archaeological Approches to Ceramics. Papers presented at EMAC '05, 8th European Meetimg on Ancient Ceramics, Lyon 2005, (2007), p. 57-62. 
